\title{
MHD Technology Transfer, Integration and Review Committee
}

\section{Semi-annual Status Report}

Period of Performance:

July 1988 - March 1989

Report No. MHD-ITC-89-307

Prepared for

U.S. Department of Energy

Pittsburgh Energy Technology Center

Pittsburgh, Pennsylvania
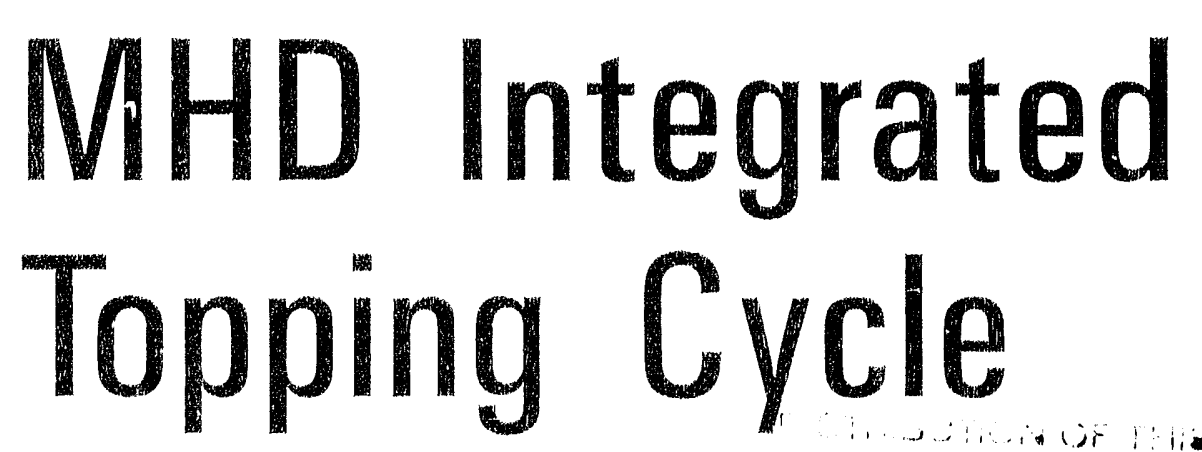


\section{Notice}

This report was prepared as an account of work sponsored by the United States Government.

Neither the United States nor the United States

Department of Energy, nor any of their

employees, nor any of their contractors, subcontractors, or their employees, makes any warranty, express or implied, or assumes any legal liability or responsibility for the accuracy, completeness or usefullnes of any information, apparatus, product of process disclosed, or represents that its use would not infringe privately owned rights. 
MHD TECHNOLOGY TRANSFER, INTEGRATION AND REVIEW COMMITTEE

Second Semi-Annual Status Report

July 1988 through March 1989

MHD Integrated Topping Cycle Project

Report No. MHD-ITC-89-307

Date Submitted:

October 1989

Prepared for:

U.S. Department of Energy

Pittsburgh Energy Technology Center

By:

Applied Technology Division

TRW Space and Technology Group

One Space Park

Redondo Beach, CA 90278

Contract Number:

DE-AC22-87PC90274

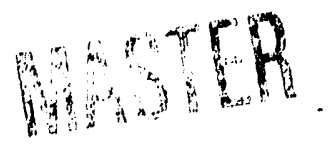


TABLE OF CONTENTS

Tab No.

Summary. . . . . . . . . . . . . . . . . . . 1

Integrated Topping Cycle . . . . . . . . . . . . 2

Integrated Bottoming Cycle . . . . . . . . . . . 3

Bottoming Cycle Component Testing - CFFF . . . . . . . . . 4

Seed Recovery/Regeneration

TRW. . . . . . . . . . . . . . . . 5

Babcock \& Wilcox . . . . . . . . . . . . . . 6

Argonne National Laboratory. . . . . . . . . . . . 7

University of Tennessee Space Institute. . . . . . 8

Retrofit Conceptual Designs

Westinghouse ................ . . 9

MHD Development Corporation. . . . . . . . . . . . . . 10

Component Development and Integration Facility . . . . . 11

TTIRC Meetings

Executive Committee - October 1988 - Summary . . . . . 12

General Committee - January 1989 - Session 1..... . 13

General Committee - January 1989 - Session 2.... . 14

Distribution . . . . . . . . . . . . . . . 15 


\section{SUMMARY}

As part of the MHD Integrated Topping Cycle (ITC) project, TRW was given the responsibility to organize, charter and co-chair, with the Department of Energy (DOE), an MHJ Technology Transfer, Integration and Review Committee (TTIRC). The Charter of the TTIRC, which was approved by the DOE in June 1988 and distributed to the committee members, is included as part of this Summary. As stated in the Charter, the purpose of this committee is to: (a) review all Proof-of-Concept (POC) projects and schedules in the national MHD program; to assess the ir compatibility with each other and the first commerical MHD retrofit plant; (b) establish and implement technology transfer formats for users of this technology; (c) identify interfaces, issues, and funding structures directly impacting the success of the commercial retrofit; (d) investigate and identify the manner in which, and by whom, the above should be resolved, and (e) investigate and assess other participation (foreign and domestic) in the U.S. MHD Program. The DOE fiscal year 1989 MHD Program Plan Schedule is included at the end of this Summary.

The MHD Technology Transfer, Integration and Review Committee's activities to date have focused primarily on the "technology transfer" aspects of its charter. It has provided a forum for the dissemination of technical and programmat ic information among workers in the field of MHD and to the potential end users, the utilities, by holding semi-annual meetings. The committee publishes this semi-annual report, which presents in Sections 2 through 11 capsule summaries of technical progress for all DOE Proof-of-Concept MHD contracts and major test facilities.

In the future, TRW and the the TTIRC will assume a more active "integration and review" role in the POC program. With completion of the retrofit conceptual designs and the selection of the Phase II seed regeneration contractor, the task of integrating the POC program can proceed with increased intensity. The overall MHD system integration effort will encompass all the major projects in the POC program, i.e., the Integrated Topping Cycle, Integrated Bottoming Cycle, Seed Recovery/Regeneration process, and Retrofit Conceptual Designs, which are compiling the technical data base needed to scale MHD to retrofit power plant sizes. TRW and the TTIRC Executive Committee are in the process of reviewing schedules, test plans, test results, design requirements, and system studies for POC program activities to ident ify technology "gaps" and incompatibilities among the various POC projects which could lead to collection of an incomplete technical data base. Under the auspices of the committee, engineering studies wi11 be performed, technical and programmatic evaluations will be conducted, and recommendations will be made to the DOE on ways to enhance the effectiveness and efficiency of the integrated Proof-cf-Concept program so as to minimize the risks of proceeding with an MHD plant retrofit. 
CAARTER POR TAE MAD TECANOLOCY TBAHSEER.

MTEGRATION ARD REPTEW COMATTHEE

This Charter has been prepared under Contract Bo. DE-AC22-87PC90274 for the O.S. Department of Energy (DOE), Pittsburgh Energy Technology Center (PETC) by IRU Inc., She prine contractor for ard Integrated Topping Cycle (ITC) Project

\section{GRARTER - ARTICLES}

The purpose of the WHD Technology Iransfer, Integration and Review Comittee (MRD TIRC) is to:

1. Review all Proof-of-Concept (POC) projects and schedules to assess their conpatibility with each other and the first comercial MRD Retrofit Plant.

2. Eotabliob and implement an appropriate technology transfer format for potential future users of MaD technology.

3. Identify integration interfaces, technical iseues, and funding otructures that have direct impact on the success of the first comercial ard retrofit plant and accessful MBD entry into the comercial narketplace.

4. Investigate and identify the anner in whicb and by whom, the above interfaces, issues and otructures sould be resolved.

5. Investigate and asess the potential for other participation, both foreign and domestic, in the O.S. MD program, including the first comercial MED retrofit plant.

\section{CHARTER - MERABRSAIP}

The ald Technology Tranafer, Integration and Review Comittee is comprised of:

The Department of Inergy

Prime contractor for the MD Integrated Topping Cycle

Prime contractor for the WaD Integrated Bottoming Cycle

The contractor for the MHD Combustor

The contractor for the XHD Channel

The contractor for the IHD Power Conditioning

The contractor for the MHD Seed regeneration

The contractor for the MllD Retrofit Conceptual Design

Operating contractor for CDIF

Operating contractor for CFPF

Other equipaent suppliers to the utility industry

Potential users of MAD technology

Investors in MAD technology

Participating univeraities

Participating netional laboratories

\section{CHARTER - OPERATION}

\section{QRGANIZATION}

The organizational etructure of the ITIR Committee shall be in accordance vith Iigure 1. The General Comittee participanta include the organizations 
Iavolved in the Topping Cycle, Bottaming Cycle, Seed Regeneration, Retrofit Conceptual Design, potential future users of mD, Oniversities and other parties cost sharing in the progrm. Proposed changes to the listed Comittee Charter Memberabip or organizational participants of Figure 1 will be accomplished only as discussed berein.

\section{GDNERAT COMATTUEE MRETINGS}

The frequency of the General Comittee neetinga will be semi annually, witb a angle participant from eacb orgenization attending, plus Bxecutive Committee nembers. The MRD ITIR Geaeral Comittee ohall neet at alternate $0 . S$. east or west locations, beginaing with the June 1988 swa neeting in Tennessee, at a location to be determined. The neeting dates and locations will be selected by the Executive Comittee nember.

The meetings will be cochaired (presidiag alternately) by Gary z. stasts of DOE/PETC and Willim H. Irving of WM, Inc. Each participating organization chall abmit a person's ame and an alternate to be responaible to the Coumittee for accomplishent of the Charter Articles. The IRW Deputy Chairman for Operatione, in conjunction witb the Comittee Cochairmen, will achedule the netings, arrange for the accomodations, prepare the agenda, distribute the ninutes suld action items, inforn the comittee nembers of the planned Charter operation and will easentially manage the day-to-day operations of the ITIR Comittee. The agenda for the first comittee neeting vill emphasize themes, vectors and soals. The subsequent neetings will ophasize program accoaplishents, schedule status, interface isaues and other appropriate enters as defined in the Articles of this Charter.

Lieted below are the specific organization that are Charter Members in the TIIR Comittec:

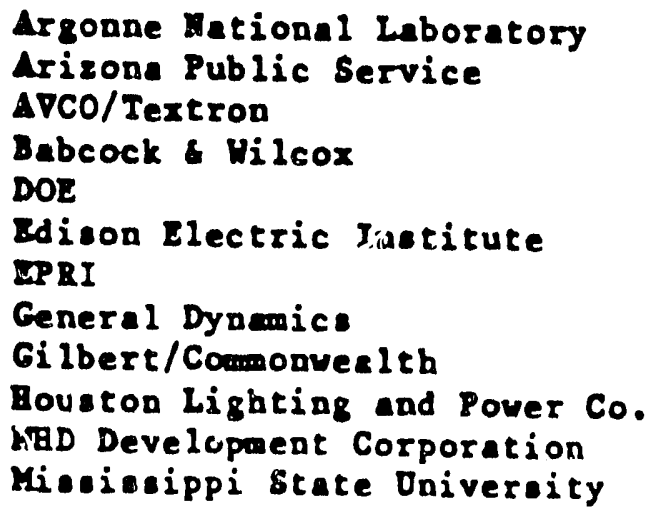

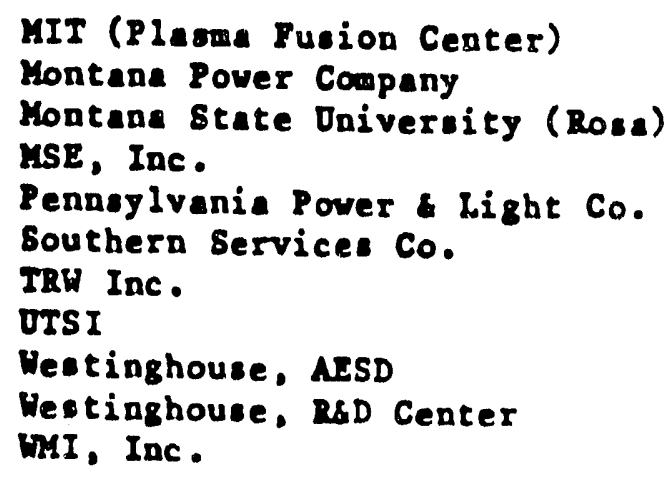



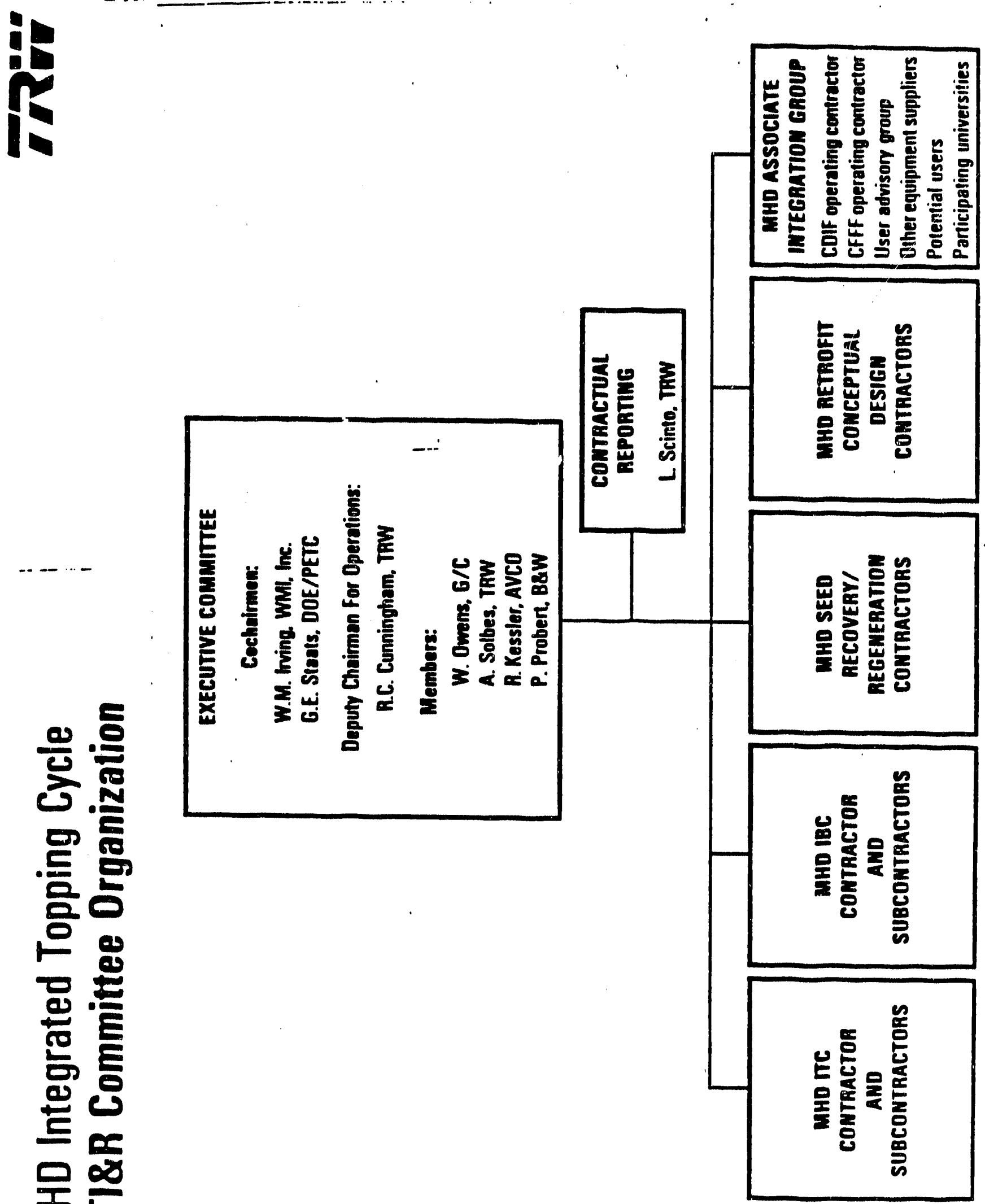

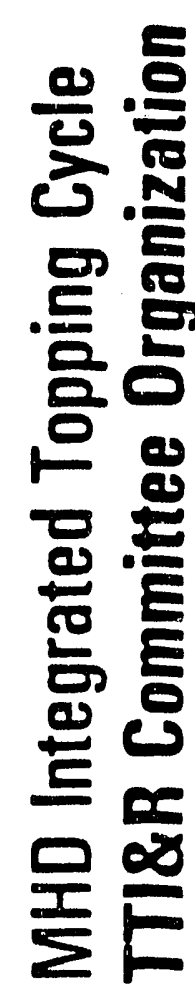


The Ixecutive Conittee will act os the Memberibip Comittee and will take care of any cbanges proposed.

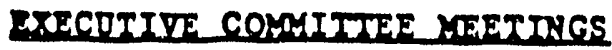

The Executive Comittee is comprised of the industry and DOE Cochairmen, the Deputy Chairmen for Operations, and Comittee nembers (see Figure 1). Election to the Executive Comittee may be accompliobed by a saple ajority including one Cochairsen constituting a quoru. This Comittee vill conrene to plan the activities of the cemi-annual General Comittee neetings, discuss salient technical integration and technology tranafer issues, and resolve other issues covered by the Articles of this Charter. The Executive Comittee is empowered to appoint subcomittees from the General Comittee nemberahip to help resolve any opecific isoues covered by this Charter. The neeting dates and locations will be selected by the Comittee Cochaimen and the Deputy Chaiman for Operation yill again ake all arrangenents, etc.

\section{SEYI-ANRTAI COATRACTUAT REPORTS}

IRW will prepare cemi-anaual progress reports based on inputs from MAD contractora. The seni-annual contractual report inputs oball be in rough draft format, together if possible with a Multikate Word Processing Disk (or compatible equivalent) and all original art work suitable for reproduction. All report inputs will be due at: IRW vithin 30 days after the General Comittee neetings. These ceni-spgual progress reports, including a collation of the vaD IIIR Coumittee neeting ninutes, will be combined and distributed. 


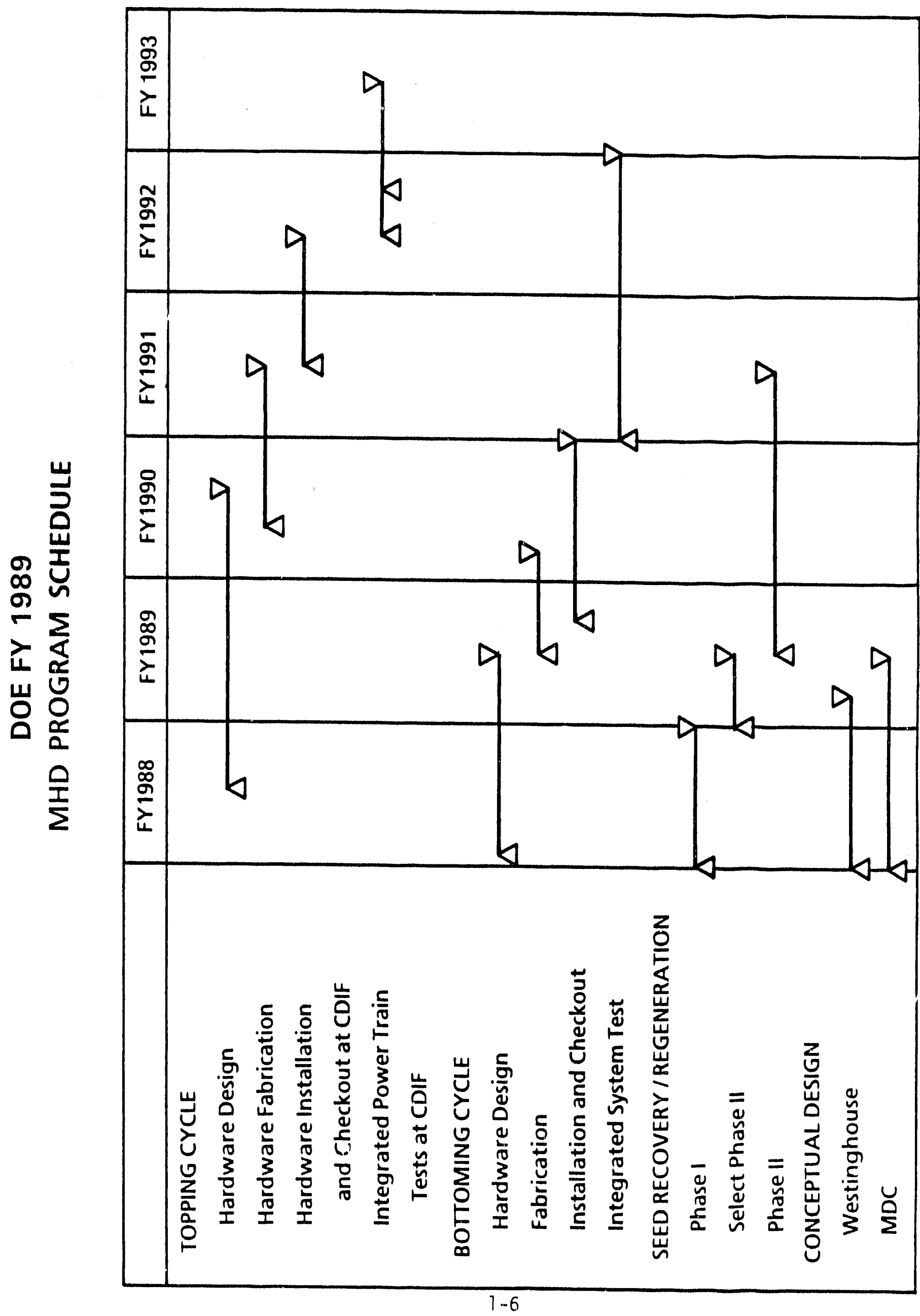

$\infty$
8
0
0
$\vdots$
$\vdots$ 
CONTRACT TITLE:

DATE:

MHD Integrated Topping Cycle

January 1989

DE-AC22-87PC90274

PRIME CONTRACTOR:

REPORTING PERIOD:

TRW Space and Technology Group

One Space Park; Redondo Beach, CA 90278

JuTy 1988 to

January 1989

MAJOR SUBCONTRACTORS:

Avco Research Laboratory/Textron

Westinghouse Research and Development Center

PROJECT MANAGER:

PERIOD OF PERFORMANCE

J.M. Bauer

(213) 814-0245

$9 / 30 / 87$ to

$9 / 28 / 92$

\section{CONTRACT OBJECTIVE}

The objectives of this effort are to design, construct and deliver all prototypical hardware necessary to conduct long-duration integrated MHD topping cycle proof-of-concept tests at the Component Development and Integration Facility in Butte, Montana, and to complement the existing engineering data base so as to allow scale-up of the MHD power train to an early-commercial scale retrofit MHD power plant.

\section{TECHNICAL APPROACH}

In order to achieve the program goal of demonstrating the durability arid reliability of critical MHD topping cycle components at the $50 \mathrm{MW}$. scale, prototypical hardware will be operated at the CDIF for over 1000 hours. In general, the approach capitalizes on the existing R\&D data base to design, fabricate, check out, deliver, integrate and test new prototypical power train components. Specifically, the following tasks will be performed:

Task 1 - Systems Engineering Studies

Task 2 - Prototypical Combustor Design, Fabrication and Delivery

Task 3 - Prototypical Channel Design, Fabrication and Delivery

Task 4 - Diffuser Section Design, Fabrication and Delivery

Task 5 - Power Conditioning Design, Fabrication and Delivery

Task 6 - Test Engineering Activities at CDIF

Task 7 - Hardware Repair/Replacement

Task 8 - MHD Technology Transfer, Integration and Review Committee

Task 9 - Quality Assurance

Task 10 - Integrated Project Management 


\section{PROGRESS SUMMARY}

\section{Task 1 - Systems Engineering}

Systems engineering activities focused on defining and documenting prototypical power train operating conditions and system design requirements and interfaces. A draft Preliminary Design Document and a draft Quality Assurance Plan were released and a System Requirements Document is being prepared. Required modifications to the CDIF to support prototypical power train testing were defined.

\section{Task 2 - Combustor Design (TRW)}

Testing was performed with a one-third scale plexiglass model of the $50 \mathrm{MW}_{\mathrm{t}}$ combustor (see Figure 1). The model was used to characterize the effects on mixing of different second stage oxidizer injection configurations. Seed distribution in the exit section of the combustor was also studied. The model is now being used to test ways to improve oxidizer mixing in the second stage and to evaluate different designs for low-pressure oxidant injection.

Additional hardware was fabricated to simulate the possible design configurations which could be used in a prototypical combustor to support Phase 2 of design confirmation testing on the $50 \mathrm{MW}_{t}$ workhorse combustor at TRW.

A $20 \mathrm{MW}_{\mathrm{t}}$ coal combustor test program was conducted at Avco using an Avco oil-fired ash-injected combustor and a TRW second stage duct. The test program concentrated on identifying the effects of slag carryover and two-stage combustion on the performance of the MHD generator. Test results indicated that (1) the axial position of the second stage oxidizer injector is a significant parameter in power train performance, and (2) second stage mixing and generator performance is sensitive to the spatial distribution and mixing of the oxygen injectors.

Prototypical combustor design activities focused on design requirements development, materials studies, and design configuration analyses. Both the materials studies and configuration analyses identified new and potentially better approaches to the prototypical combustor design. A new TRW design concept was developed for cooling the prototypical combustor which utilizes modular cooling panels. The new design offers improved maintainability and scaleability over a tube-membrane design. A $20 \mathrm{MW}_{\mathrm{t}}$ combustor spool piece was designed which employs these cooling panels. It will be fabricated, and then tested in the Avco Mark VI facility in 1989.

\section{Task 3 - Channel Design (Avco)}

An engineering development task for improved sidewall (i.e., insulating wall) Iife is included as part of the Avco ITC program to ensure that the lifetime requirement of the prototypical channel $(2000$ hrs) will be met. Sidewalls are the life-limiting component of coal-fired MHD channels because they support the highest electric fields, the 


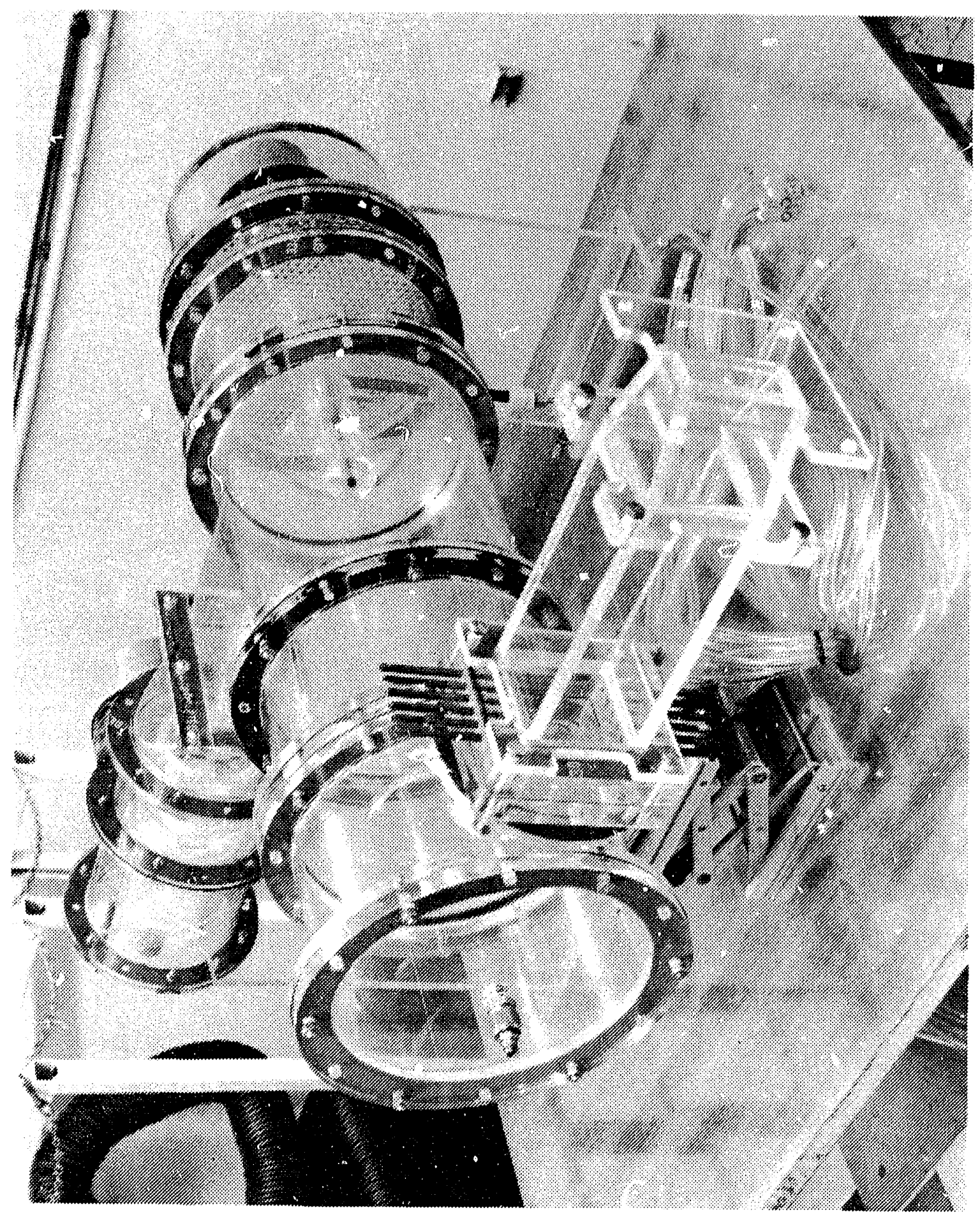

Figure 1. Cold Flow Model 
transverse Faraday field plus the axial Hall field. Recent investigations include several engineering approaches to minimize the problems caused by cathode slag polarization (iron-oxide injection and modified electrode wall designs). Several experiments were also carried out to help understand the physical mechanisms responsible for creating the high voltage insulator gaps and to assess the feasibility of controlling the slag resegmentation frequency by external switching circuits (slagging/external shorting experiments). Finally, the effects of cathode shorting on the overall channel operating characteristics were studied (bare wall/external shorting tests).

Another approach to increase channel wall (electrode walls and sidewalls) life is to develop alternative designs and/or to select suitable corrosion resistant cladding materials for the wall elements. Duration tests are currently underway in the Avco Mark VII facility to identify potential candidates for electrode and sidewall materials and designs. These generator tests are being conducted under prototypical operating conditions with Rosebud ash and sulfur addition. Promising test electrode and peg configurations will later be tested in the Mark VI and CDIF coal-fired channels. Subcontracts have been awarded to several firms to develop and supply samples of ceramic/metallic clad pegs (and bars) for test in the Mark VII channel.

Modifications are being implemented on the CDIF $1 A 1$ workhorse channel side walls. The cathode side wall end pegs are being fabricated from copper capped with tungsten-copper rather than from a single tungsten-copper piece. The use of tungsten-copper capping is being incorporated into the design of the segmented bar side walls to reduce side wall wear. In addition, a design change to the side wall to cathode wall joint is being implemented to reduce arcing and burn-through of the joint gas seal. The hosing and wiring are being re-packaged to allow the channel to fit into the magnet bore without concern for interference. This measure will improve channel operational reliability while minimizing, (1) hose and wiring routing, and (2) channel to facility interconnection problems during channel installation.

Parametric studies were undertaken to study alternative prototypical channel designs and their potential gains in performance relative to the existing CDIF $1 A 1$ diagonally loaded MHD channel. Of particular interest are those channel designs that yield more favorable fluid dynamic and electrical performance. Sensitivities of generator performance to inlet Mach number, diffuser efficiency, diagonal connection, oxidant N/0, axial distribution of the cross-sectional aspect ratio, and axial leakage resistance were investigated and several candidate design were selected.

Two hundred and fifty-six prototypical current control devices for the 1 A4 channel are currently being fabricated. The manufacturing of the cabinets in which these devices will be housed are completed (see figure 2 ). The deliveries of some of the sub-assembled parts to Avco are in progress; final assemblies will take place in 1989. 


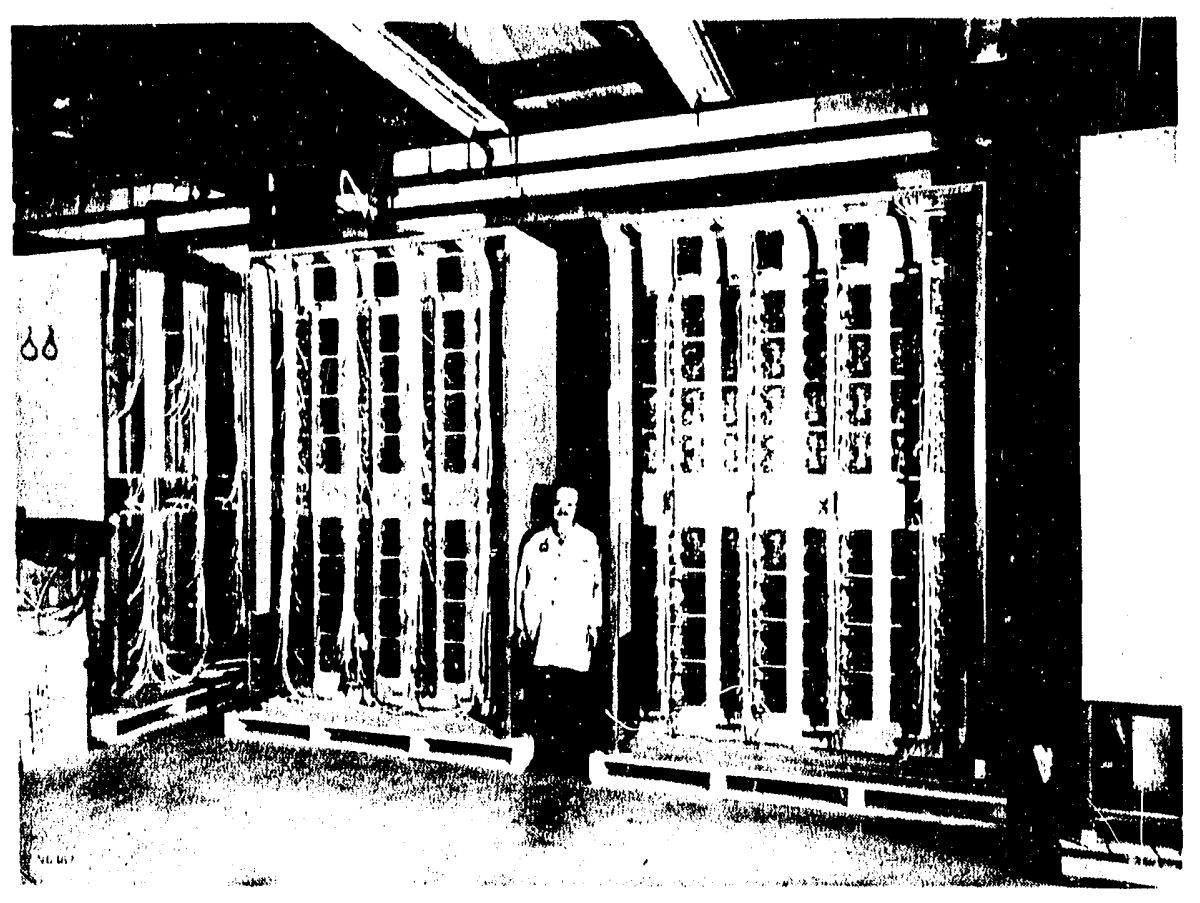

Figure 2. Current Control Cabinets 


\section{Task 5 - Current Consolidation Design Support (Westinghouse)}

This subcontract calls for development and construction of MHD power management hardware which would consolidate 30 electrodes at each end of the prototypical CDIF channel and 16 electrodes at each end of the Avco Mark VII channel. Since prior work under an Avco subcontract had been aimed toward consolidation of al1 112 electrodes of the Mark VII channel, the prior circuit designs had to be modified to the new condition of consolidating only end electrudes. A potential defining converter had to be added to the Avco breadboard hardware.

In collaboration with Avco, the requirements for the overall system were redefined, and the circuit designs were modified where necessary. Breadboard models of each of the required circuits were built and tested to verify their performance prior to proceeding with fabrication of the final hardware. Fabrication of the circuit boards for the control of the thyristors in the consolidation converters and potential defining converter has been completed. Machining of the heat sinks for the thyristors has been completed and assembly of the consolidation converter modules can now be started. All required electrical components have been ordered; over 95\% have been received and the balance are expected by the end of January 1989. The overall control scheme and considerations regarding interfaces with the Avco facility have been reviewed and resolved with Avco.

\section{Task 6 - CDIF Test Support}

TRW and Avco continued to provide engineering support and data analysis for the $50 \mathrm{MW}_{\mathrm{t}}$ workhorse power train testing at the CDIF. Testing and data analysis to improve power output remained a high priority. The most significant series of tests involved changing second stage oxidizer injection configurations. A $40 \%$ increase in channel power output was realized as a result of run condition and heat loss changes to the combustor. TRW and Avco will continue to support the testing at CDIF throughout the duration of the ITC program.

The coal-fired precombustor and continuous slag rejector assembled under the MHD Phase IV contraci were delivered to the CDIF. Installation of the CFPC was initiated. Testing is scheduled to resume in the second calendar quarter of 1989. Planning for the CFPC test series and for the prototypical Design Verification and Duration testing was begun.

\section{Task 8 - Technology Transfer/Integration}

Between July 1988 and January 1989, the Executive Committee met once and the second semi-annual General Committee meeting was held. The Committee identified programmatic and technological issues related to the retrofit of an exiting power plant. The first semi-annual (January - June 1988) TTIRC Status Report to DOE was published. 


\section{Task 9 - Quality Assurance}

A draft Quality Assurance Plan was released and QA activities were initiated.

\section{PLANNED ACTIVITIES}

The second phase of the $50 \mathrm{MW}_{t}$ workhorse combustor Design Confirmation testing will be conducted in 1989 . Prototypical design features such as domed head end closures, square slag tap openings and tubular baffle designs will be evaluated.

AIC/second stage testing will be completed, and testing of a TRW 20 $\mathrm{MW}_{\mathrm{t}}$ coal-fired combustor will be conducted at Avco in the Mark VI facility. This testing will allow optimization of combustor configurations (particularly the second stage) and evaluation of materials and designs for the prototypical channel and combustor prior to the Critical Design Reviews.

Combustor design activities will continue throughout 1989. Additional materials evaluation support will be provided by Argonne National Laboratory under subcontract.

Duration tests currently under way in the Mark VII will continue in order to identify potential candidates for electrode and sidewall materials and designs. Prototypical channel design and engineering activities will carry on in preparation for the Preliminary Design Review. The current control fabrication and assembly activities are scheduled to be completed in mid-1989.

Assembly of the current consolidation converters and the potential defining converter will continue and completion of fabrication is scheduled for April 1989. Assembly of the control and instrumentation hardware and writing of the software will begin in February 1989, and will be completed by the end of April. During May, all assembled hardware modules will be pretested and debugged. During June, the complete system will be tested prior to delivery to Avco.

\section{SCHEDULE}

A copy of the overall schedule for the ITC project is attached. 


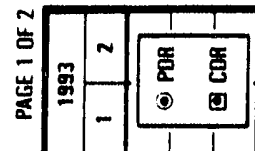

p

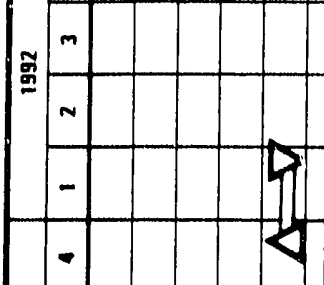

疍

$\frac{m}{n}$

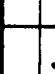

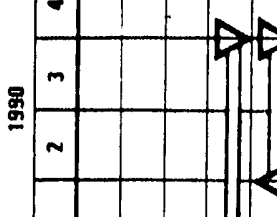

- 15
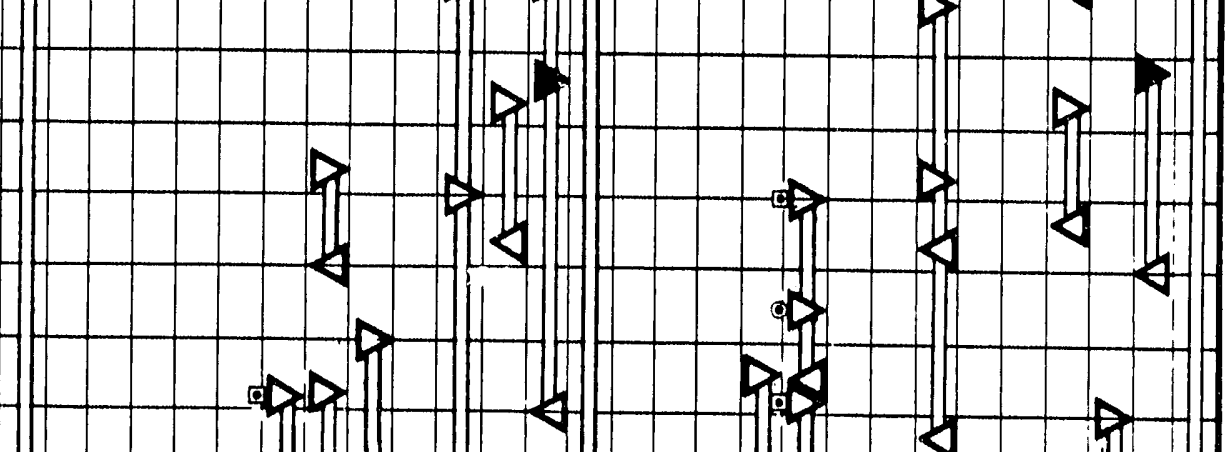

\begin{tabular}{lll||l|}
\hline- & & \\
\hline$m$ & & & \\
\hline & & & \\
\hline
\end{tabular}

政

$=$

-

4

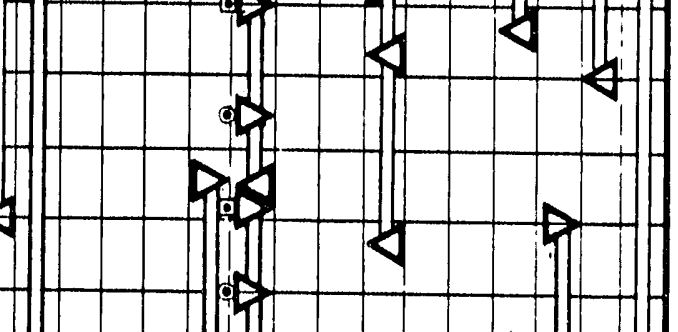

总
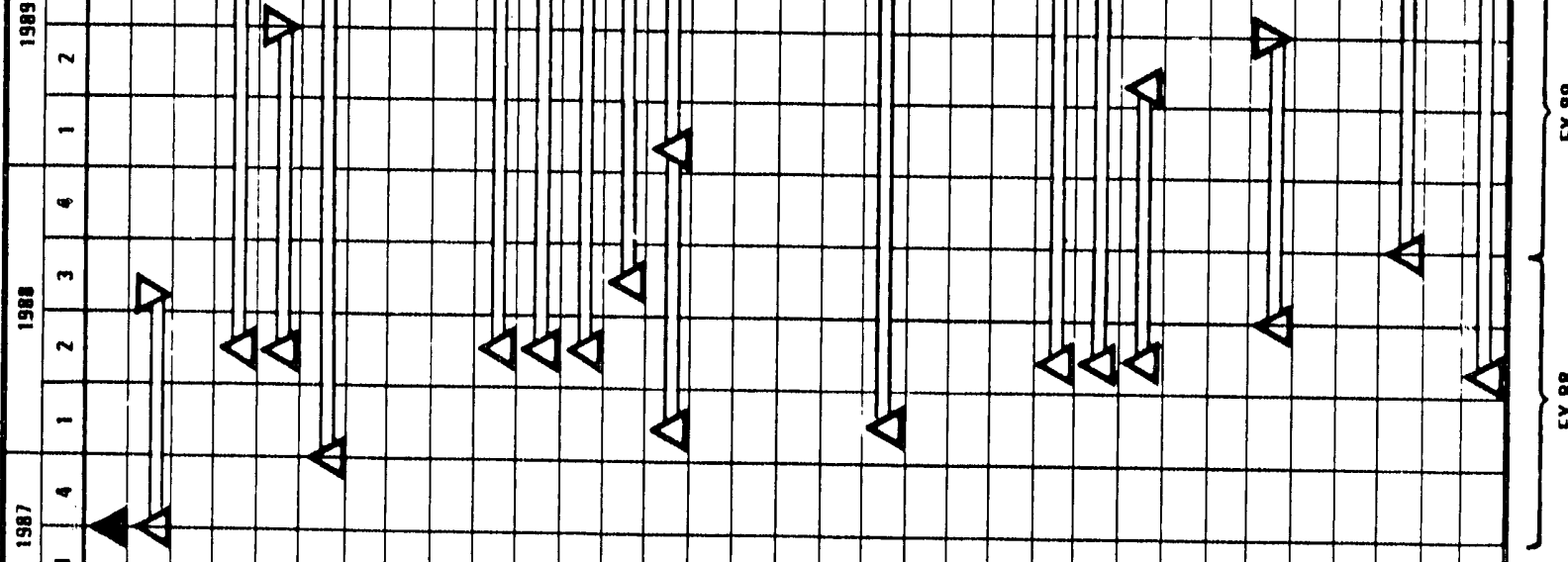

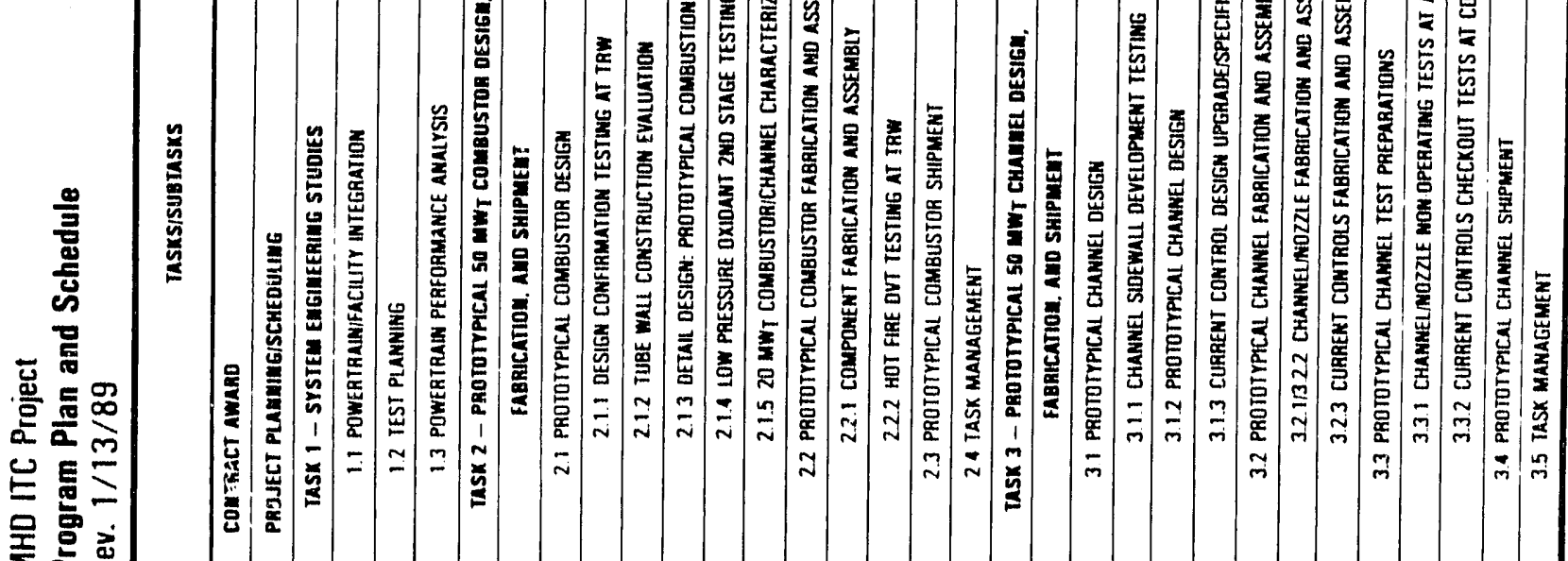

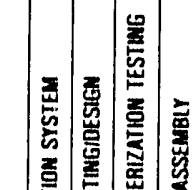




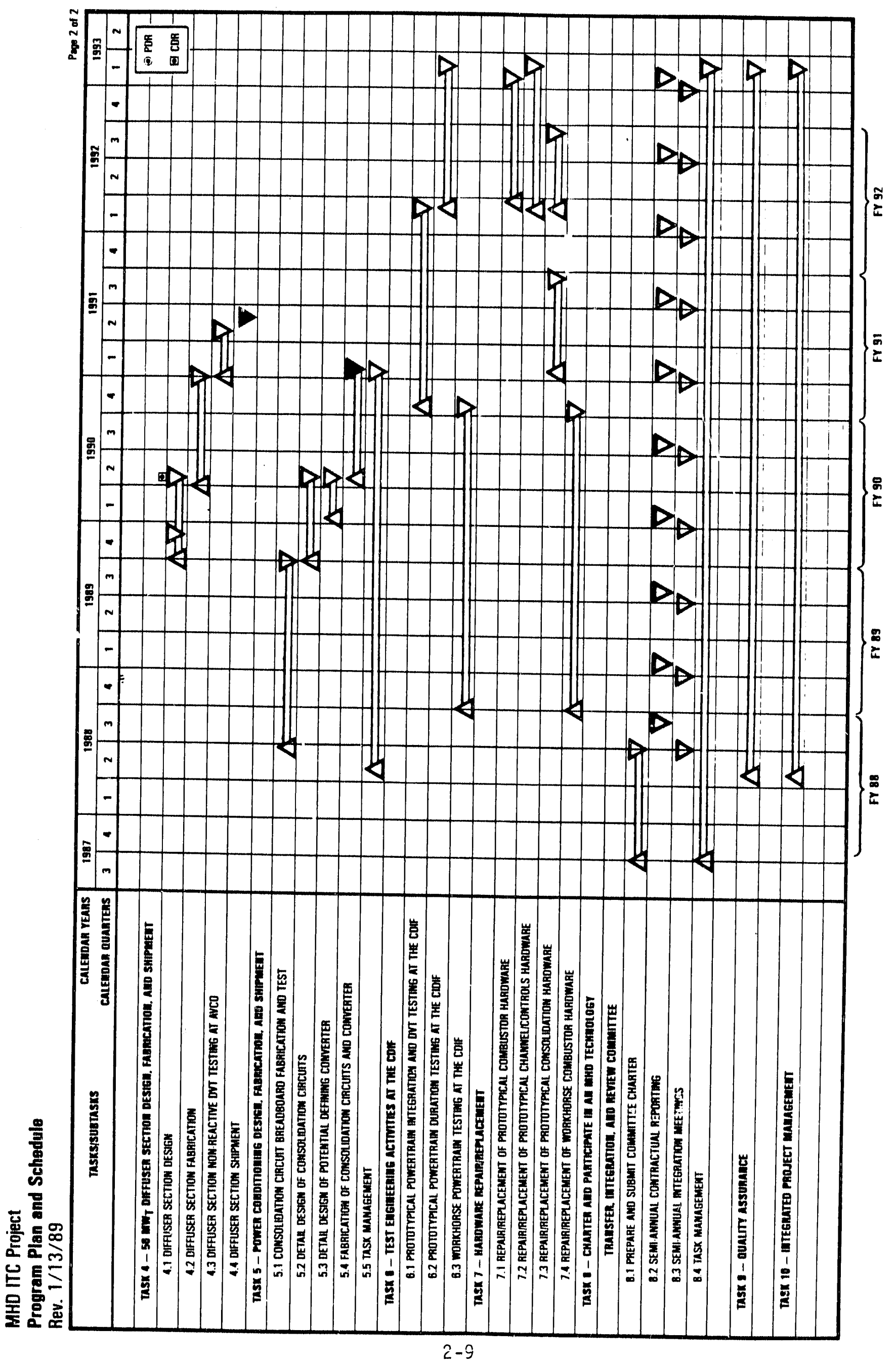


CONTRACT TITLE AND NUMBER:

Integrated MHD Bottoming Cycle

DE-AC22-87PC 90281

CONTRACTOR:

Babcock \& Wilcox Company

1562 Beeson Street, Alliance, OH 44601

PROJECT MANAGER:

Paul B. Probert

(216) 829-7494
DATE:

March 8, 1989

REPORTING PERIOD:

July 1,1988 to

December 31, 1988

PERIOD OF PERFORMANCE:

September 11, 1987 to

March 11, 1989

\section{CONTRACT OBJECTIVE}

Design, procure, install, and check out subsystems and components to modify or augment the existing DOE Coal-Fired Flow Facility located at the University of Tennessee Space Institute, Tullahoma, TN.

\section{TECHNICAL APPROACH}

There are four tasks:

1.) Design, procure, install modifications to the existing coal pulverizing and drying system at CFFF, to handle high moisture western coal.

2.) Design, procure, install an automated seed/ash conveying system.

3.) Prepare a design and procurement/installation enabling package for an Intermediate Temperature $\left(1200-1500^{\circ} \mathrm{F}\right)$ Air Heater.

4.) Participate in the DOE Technology Transfer, Integration, and Review Committee.

\section{PROGRESS SUMMARY}

\section{Task 1 - Modifications to CFFF to Handle High Moisture Western Coal}

Engineering analysis and data on drying of western high moisture coal in commercial pulverizers showed Montana Rosebud coal with $30 \%$ moisture cannot be dried to the required $3 \%$ moisture in the pulverizer. Bids on coal dryers were received from three vendors. Suitable quantities of $3 / 4$ " $x 0$ Montana Rosebud coal were sent to the three vendors (representing fluidized bed, tray, and steam tube rotary dryer types). Visits were made by representatives of DOE/PETC, Gilbert Commonwealth, and B\&W to each of the three vendors to witness coal drying demonstration tests in their type equipment. The Wyssmont tray type dryer was recommended for installation at CFFF. 


\section{Task 2 - Automated Seed/Ash Handling System}

This system will collect seed/ash mixture from the various superheater hoppers, baghouse and electrostatic precipitator, weigh it, and transport it to the existing spent seed storage tank for disposal. Samples of seed/ash mixture from CFFF were sent to vendors for their evaluation prior to submitting bids. A visit to Macawber, Inc. was made by representatives of DOE/PETC, Gilbert Commonwealth, Hudson Engineering, and B\&W to witness a demonstration of the Macawber Densveyor system handiing CFFF seed/ash mixture. This trip al so included a commercial installation of a Macawber system handling particulate material in a large malleable iron foundry. The comments from the Preliminary Design Review have been incorporated in the design report.

\section{PLANNED ACTIVITIES}

It is planned to conduct a Preliminary Design Review on the modifications to the coal drying and pulverizing system and a Critical Design Review on the automated seed/ash conveying system at CFFF in early February, 1989. 
CONTRACT TITLE AND NUMBER MHD Bottoming Cycle Component Testing at the Coal Fired Flow Facility DE-AC02-79ET10815

\section{CONIRACTOR}

The University of Tennessee Space Institute Tullahoma, TN 37388

PRINCIPAL INVESTIGATOR

Joel W. Muehlhauser

(615) 4ं5-0631
DATE

January 26, 1989

\section{REPORTING PERIOD}

July 1988 through

December 1988

PERIOD OF PERFORMANCE

March 1988 through

April 1989

\section{CONTRACT OBJR.CTIVES:}

(No Change)

2. TECHNICAL APPROACH:

(No Change)

\section{PROGRESS SUMMARY:}

During this reporting period, two tests were conducted at the CFFF. These tests added 353 hours to bring the cumulative total of POC testing with Illinois \#6 coal to 856 hours.

LMF4-0 - The objective of this test was to run continuously for 100 hours and accumulate a total of 250 hours overall. The test was conducted in September and both objectives were accomplished. The total time of operation was 252.1 hours with the longest continuous portion being 111.5 hours. No significant problems were observed with any of the flow train components.

LMF4-P - The objective of this test was to operate for 100 hours and obtain data on sootblowing pressures and the ease of ash removal from the ESP with increased outlet diameter and vibrators installed. The test was conducted successfully in November with a total of 101.3 hours.

A sootblowing experiment was conducted during LMF4-P with a fixed $1 / 2$ inch nozzle positioned 9.75 inches in front of a TS1 tube. The objective was to determine the required peak impact pressure (PIP) required for effective deposit removal. Ten second blows at 5 successively higher impact pressures were made at intervals of 50,150 , and 300 minutes during the course of the test. Percent deposit thickness removal by each blow 
was determined from video recordings. Curvefits to the resulting data indicate that cleaning can be achleved, at least for the short term. Also, the curves trend upward beyond about 40 hours, indicating Improving rather than worsening cleaning with time. This test, and LMF4-0, was conducted with the molar $K_{2} / S$ ratio $<1.1$.

During LMF4-0 and LMF4-P, the flow rate through the ESP was varied in a series of steps to determine the effect of specific collection area (SCA) on particulate collection efficiency. According to the Deutsch equation of precipitator performance, the efficiency should be proportional to the exponential of the SCA. Although some data scatter was observed, preliminary results indicate for the conditions evaluated that an SCA of $400-450$, may meet the NSPS standards. In future testing, more data vill be collected for other conditions at various specific collection areas.

\section{PLANNED ACTIVITIES AND SCBRDULE:}

Long duration proof-of-concept testing will be continued on Illinois \#6 coal during the period January 1, 1989 through December 31, 1989, for a total of 525 hours bringing our total POC test hours on Illinols \#6 to 1381 hours. The remaining 619 hours to complete 2000 hours are planned to be completed during 1990 .

The tube spacing in the upstream portion of the SHTM are currentiy being rearranged to suit the gas temperature regime dictated by the retrofit studies. This work is plenned to be completed during April 1989 and a 100 hour checkout test performed during May 1989.

An automated ash handling system from the SHTM, AH, ESP, and BH is planned for completion in December, 1989, and the conversion of the CFFF coal processing system to handle up to 30\% moisture Montana Rosebud coal is planned for completion in September, 1990.

Shakedown tests and POC testing with the Rosebud Coal are planned to start in November, 1990. 


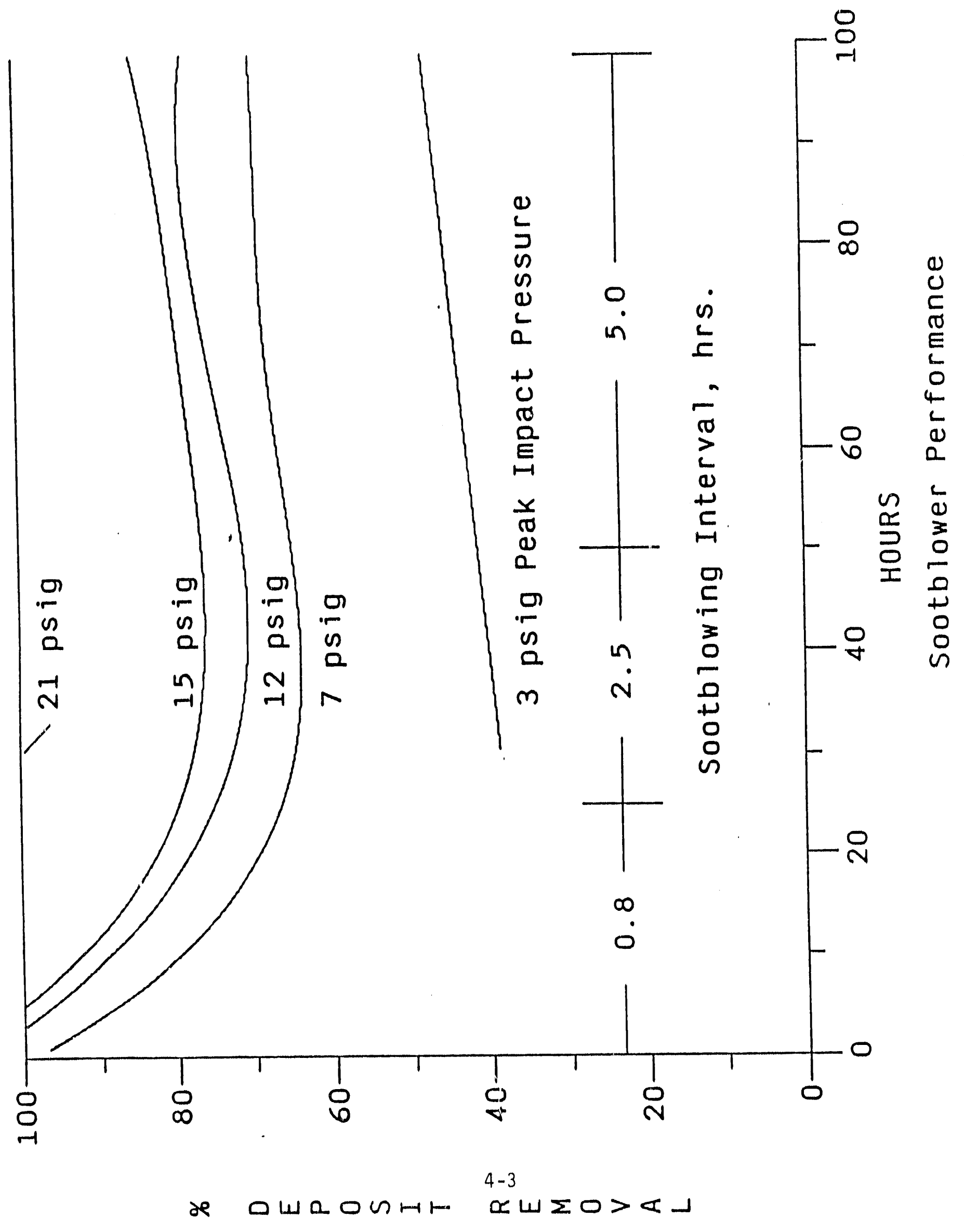



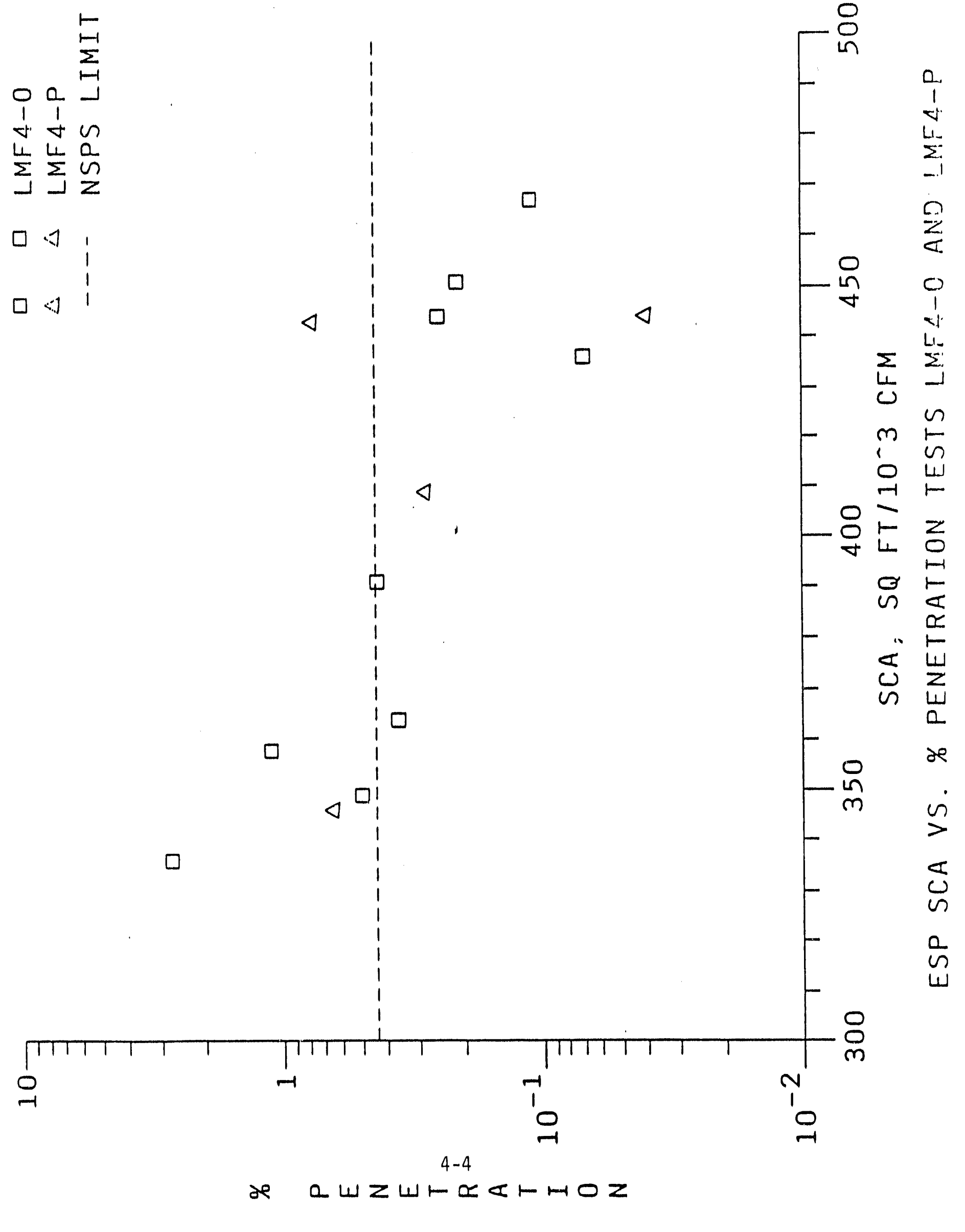


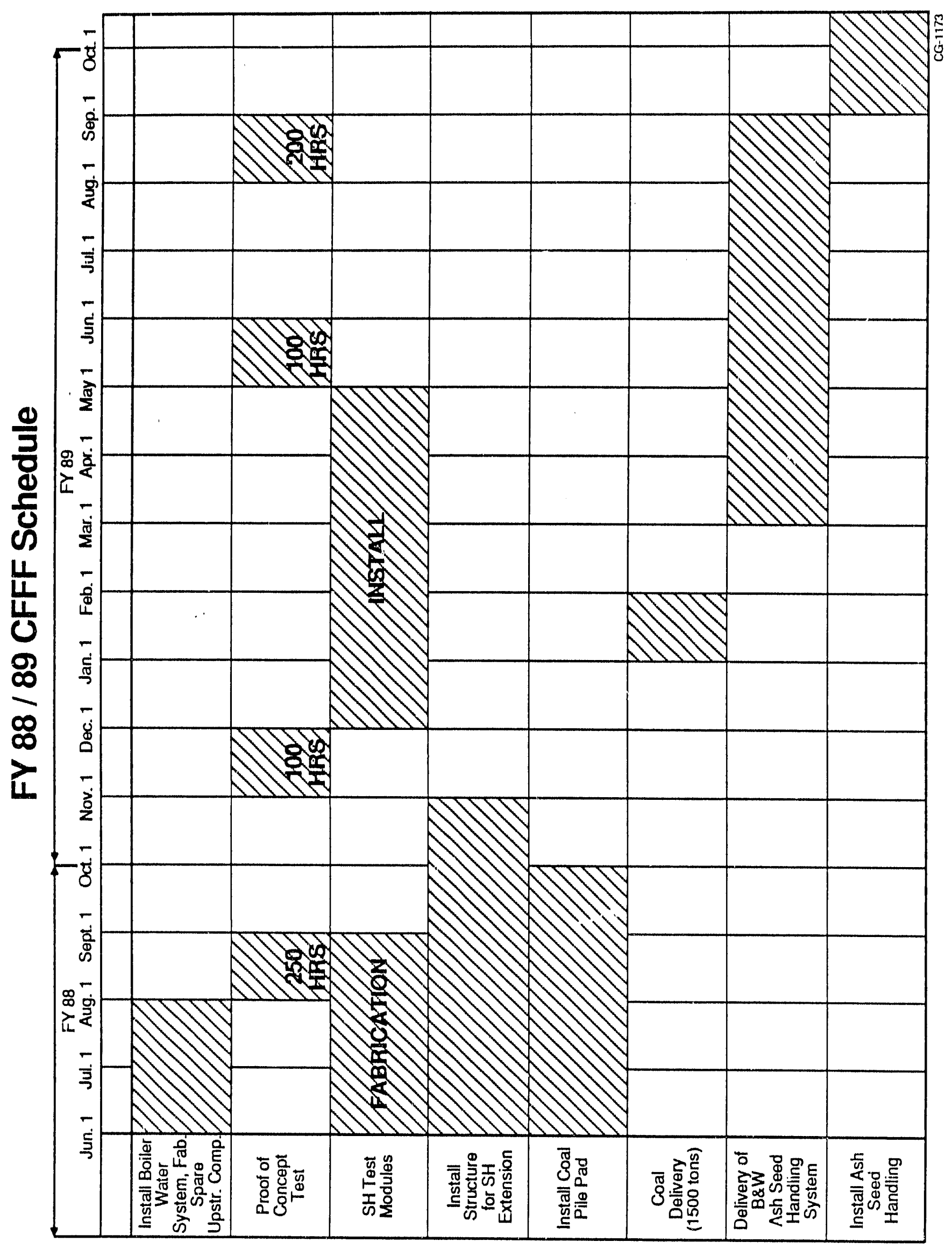




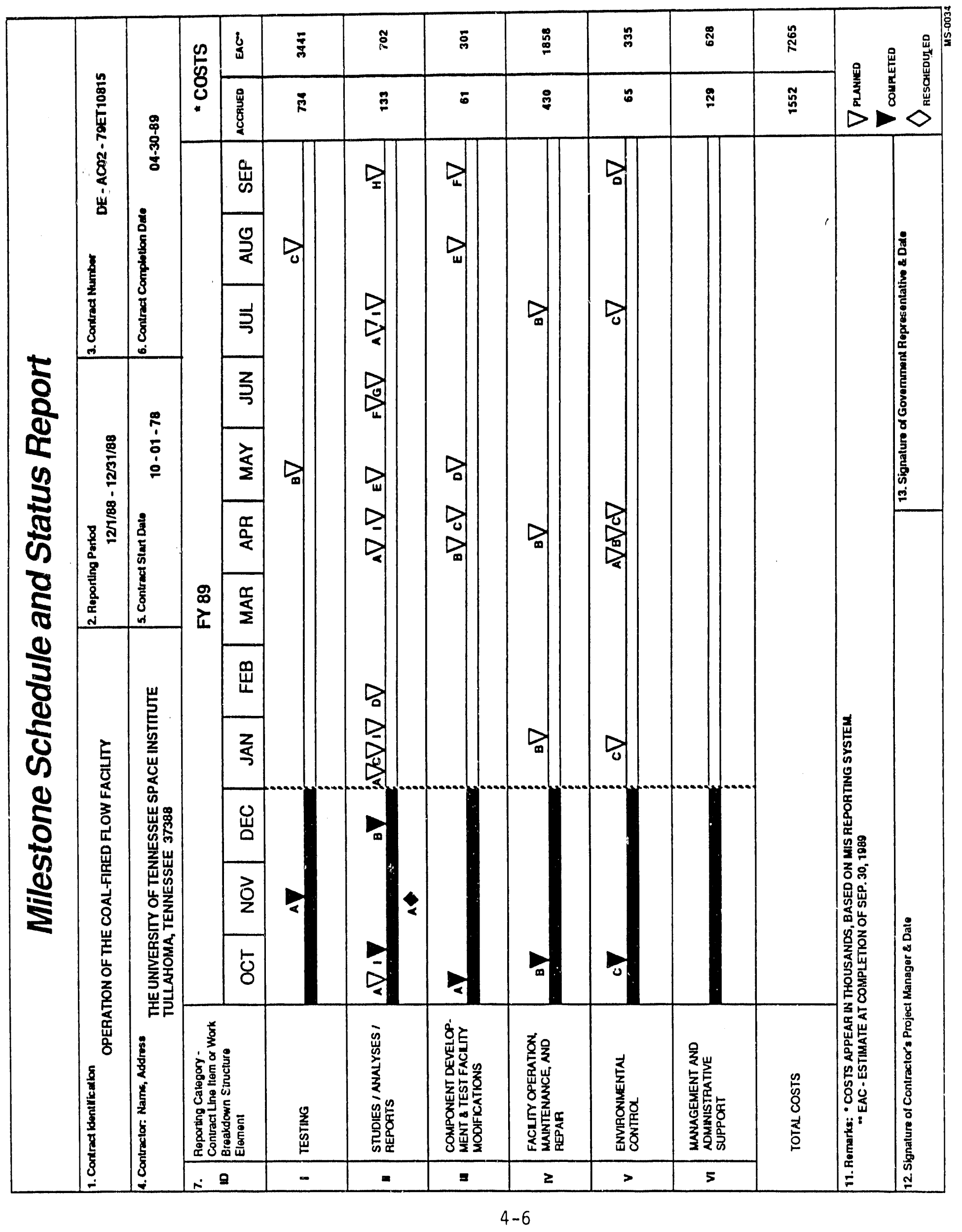




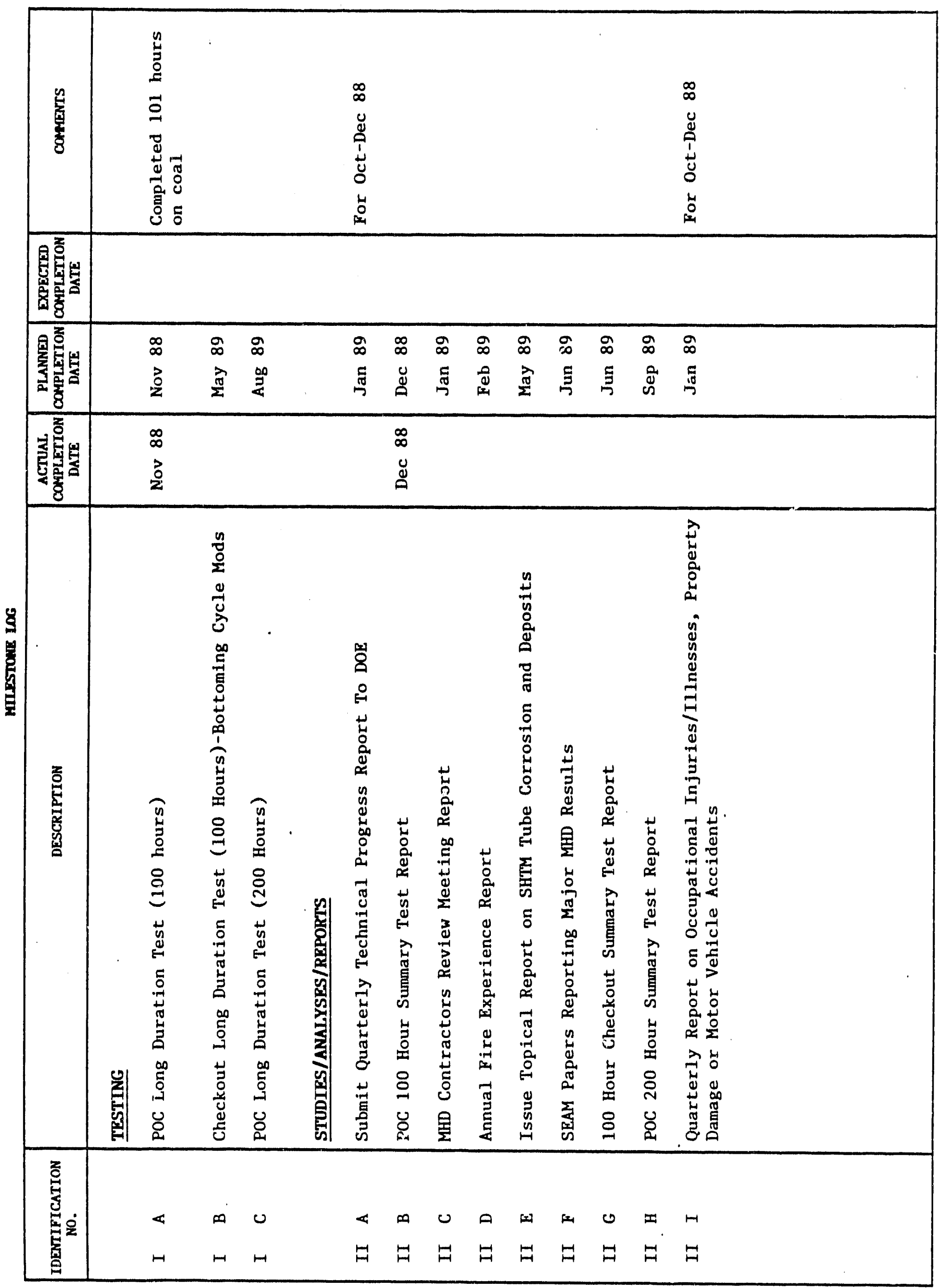




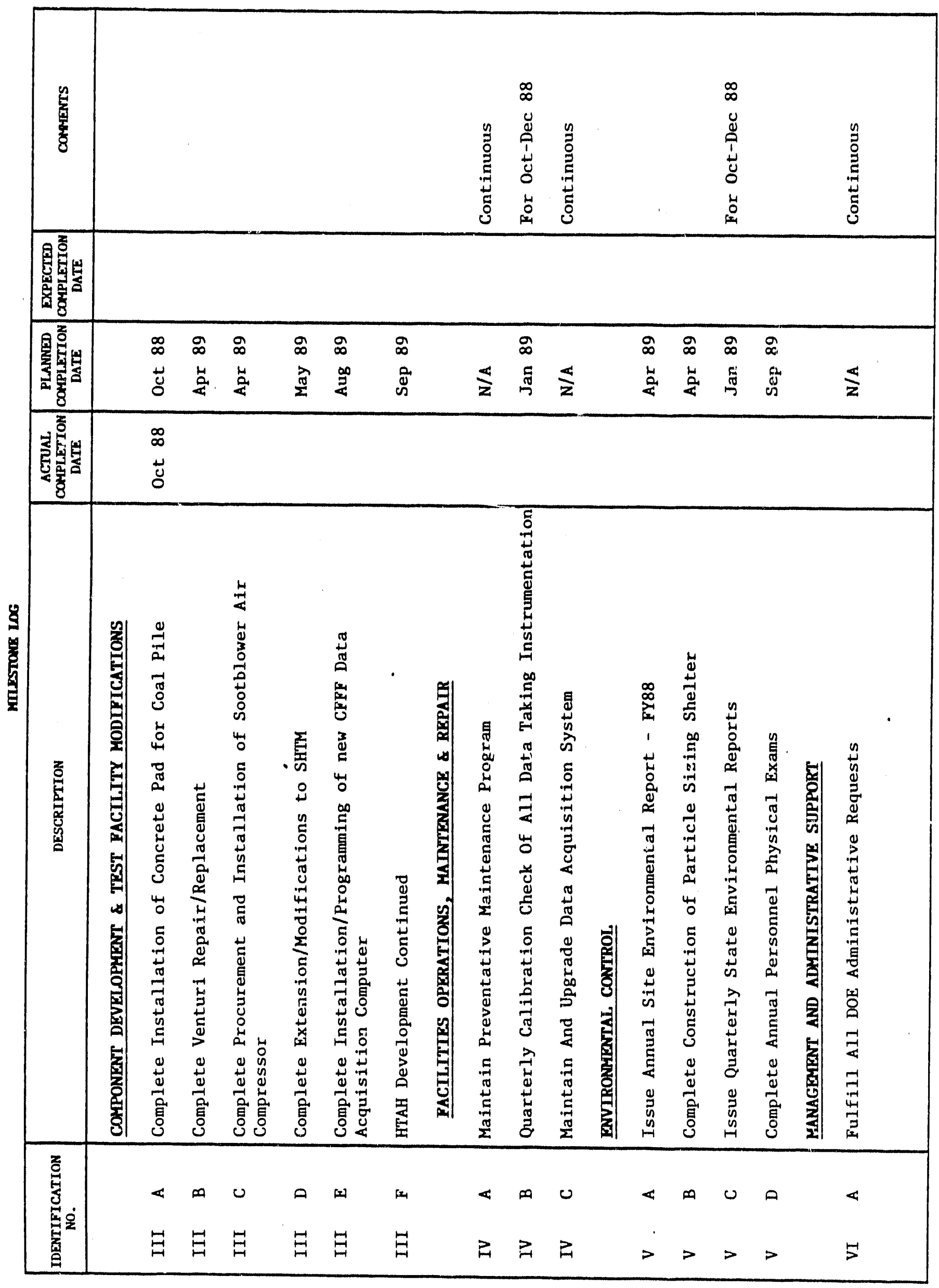




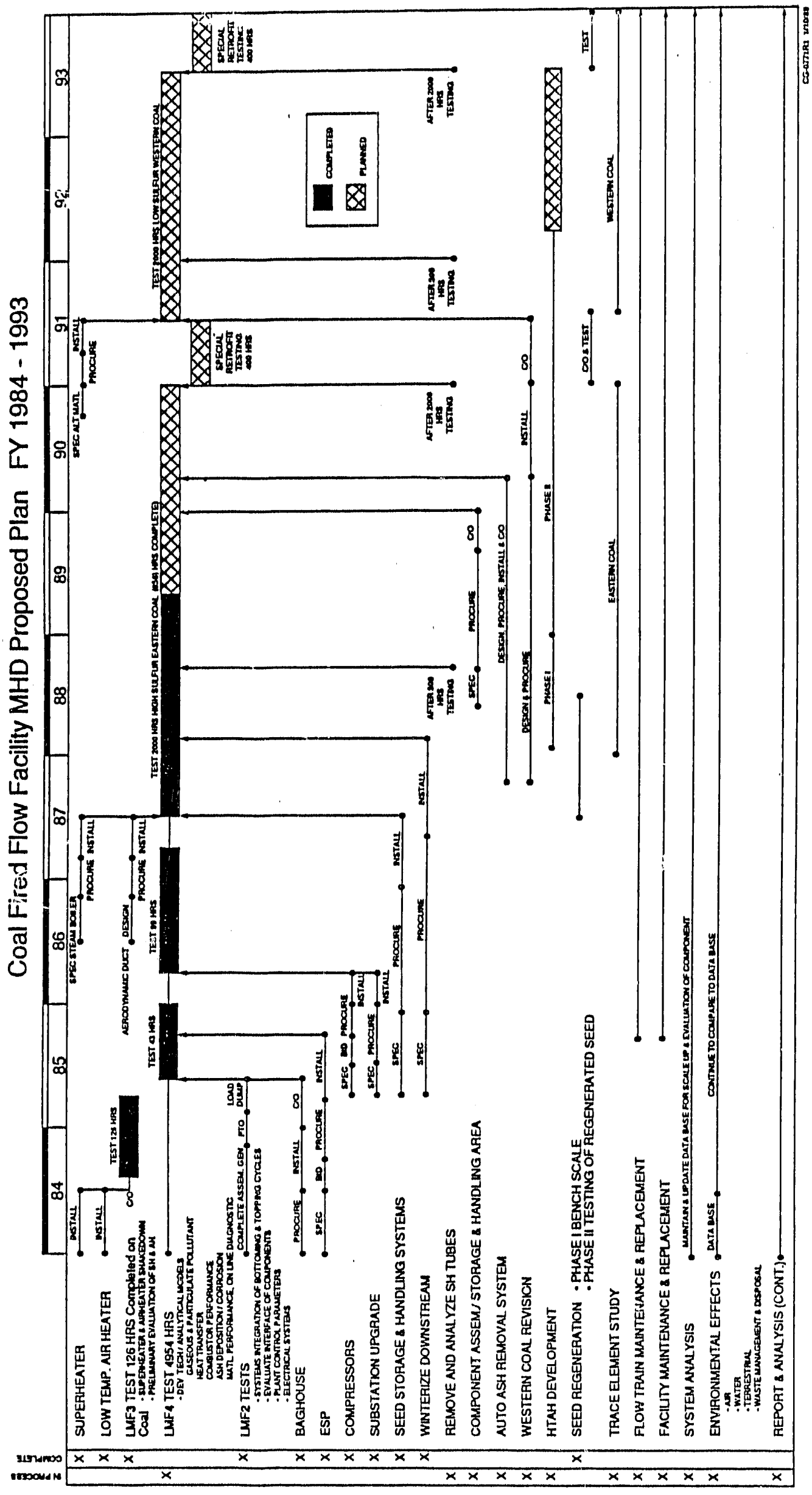


REPORT FOR MHD TECHNOLOQY

TRANSFER, INTEGRATION AND REVIEW COMMITTEE

CONTRACT TITLE AND NUMBER:

DATE:

MHD Seed Recovery/Regeneration Phase I

DE-AC22-87-PC79672

$1 / 24 / 89$

CONTRACTOR:

REPORTING PERIOD:

TRW Applied Technology

One Space Park-01/2270

$6 / 01 / 88$ to

$10 / 01 / 88$

Redondo Beach, CA 90278

With unfunded assistance by Fluor-Daniel, Inc.

Irvine, CA 92714

PROJECT MANAGER:

PERIOD OF PERFORMANCE:

Robert A. Meyers

(213) $813-9439$

$10 / 1 / 87$ to

$10 / 1 / 88$

1. Contract Objectives
a. Achieve $>90 \%$ potassium recovery and regeneration
b. Achieve target cost level $20 \%$ lower than wet limestone FGD
c. Environmentally acceptable operation
d. Designs and cost estimates for POC and $300 \mathrm{MW}(t)$ untts

\section{Technical Approach}

Utilize reaction of preformed calcium formate solution to convert spent seed potassium sulfate to potassium formate which is oxidized to potassium carbonate. This is a TRW patented technology - known as the Econoseed Process. Produce calcium formate separately in a very high throughput pressure reactor. This approach avolds potassium losses and saves considerable high pressure reactor costs.

TRW laboratory tested and patented the Econoseed Process in the early 1980's. This process has been found to operate rapldly in ambient pressure, and temperatures of about $70^{\circ} \mathrm{C}$, to provide a quantative yield of regenerated potassium seed and was estimated to provide a product that would cost approximately one half that of buying replacement potassium seed. Meanwhlle, TRW has performed several chemical processing pllot plant projects for the Department of Energy and the Environmental Protection Agency which successfully 
demonstrated technologies for coal desulfurlzation, coal water mixture hydraulics and erosion/corrosion evaluation and, presently. desulfurization and demineralization of coal. The resulting pilot faclitties (see photographs on next page) which were bullt with approximately $\$ 7 M$ of Department of Energy and TRW funds and maintained and upgraded by the TRW factlittes organization, provide a cost effectlve test bed for POC testing of the Econoseed Process. because of the importance attached to the development of MHD technology, Fluor-Daniel, Inc., has ut llized its discretionary funds to assist TRW in engineering and cost aspects of this project.

\section{Progress summary}

Engineering assessment of the data obtained in benchscale testing shows that the process is technically and economically feasible and is ready for testing at $P O C$ scale. Major conclusions are:

1. Seed can be regenerated at a total cost per unit potasslum of approximately $\$ 0.23 / 16$ in the dry potassium formate form or $\$ 0.27 / 1 b$ as dry potassium carbonate form - this is less than half the potassium cost of $\$ 0.63$ if purchasing new potassium carbonate (there would be an additional and undefined cost for spent seed flyash disposal if not regenerated.)

2. As originally proposed, extsting DOE factlittes at TRW (see photographs) are capable of use as a seed regeneration $P O C$ and can be ready in time to regenerate CFFF spent seed for the CDIF testing schedule.

3. The POC plant is a flexible unit which can be run at a nominal 250 $\mathrm{lbs} / \mathrm{hr}$ or as $1 \mathrm{w}$ as $50 \mathrm{lbs} / \mathrm{hr}$ should spent seed be in short supply.

4. Benchscale data shows no bulldup of coal derived sodium in either flyash or the seed regenerated from once-through CFFF flyash and further, the sodium content is reduced in the seed regeneration by the Econoseed Process.

5. Netther the calcium formate nor the potassium formate reactors are major cost items as the residence times are on the order of a few minutes as compared with, for example, the formate process where the two reactors are combined into one very large pressure reactor with a residence time of one to two hours.

\section{Future Plan}

TRW, together with its pre-qualified subcontractor, Fluor-Dantel, Inc., have submitted a proposal to the Department of Energy to design, construct and operate a proof-of-concept test plant for the Econoseed
Process. 

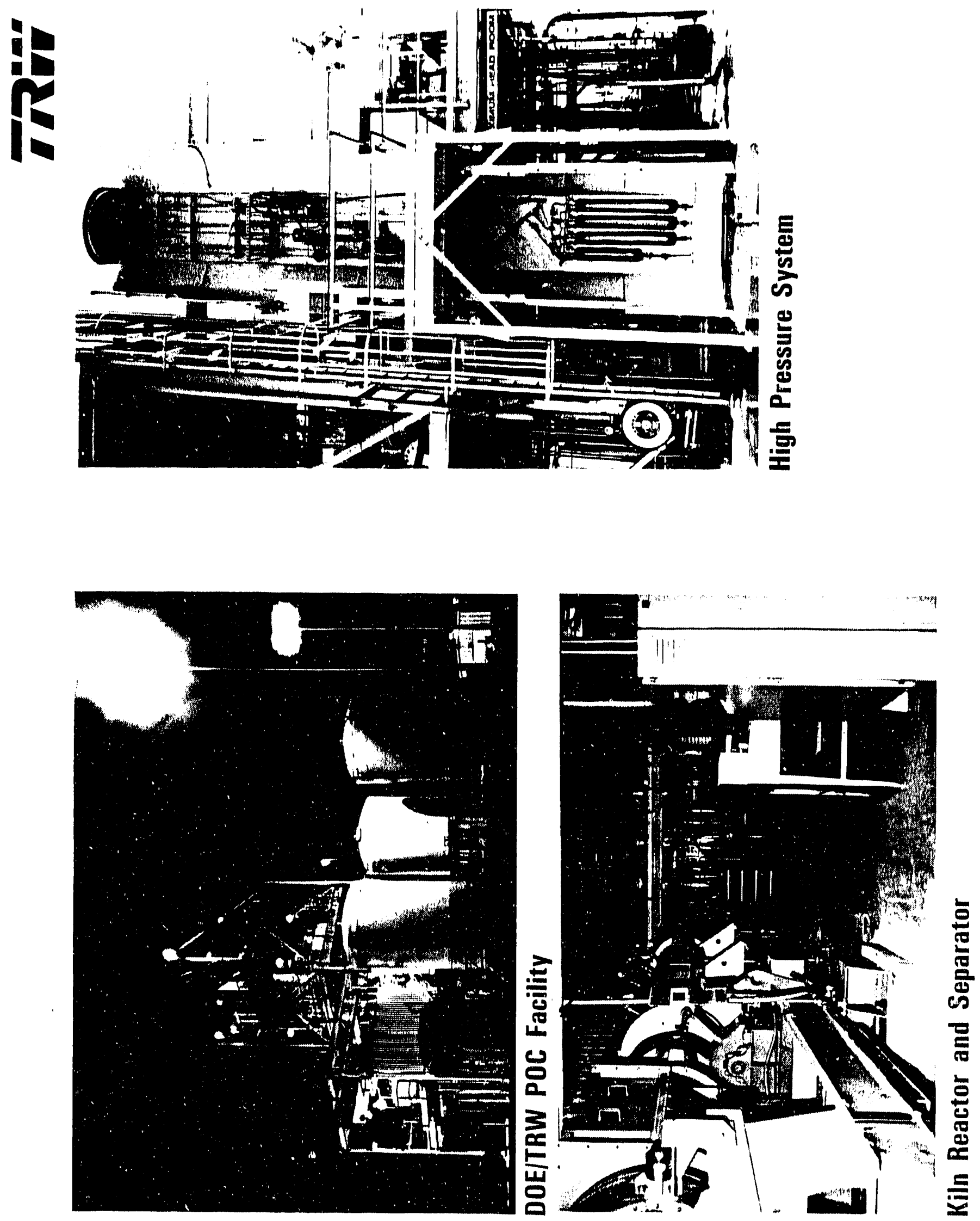
CONTRACT TITLE AND NUMBER:

ICHD Seed Recovery/Regeneration, Phase I

$D E-A C 22-87 P C 79670$

\section{CONTRACTOR:}

Babcock \& Wilcox Company

1562 Beeson Street, Alliance, $\mathrm{OH} 44601$

PROJECT MANAGER:

Paul B. Probert

(216) 829-7494
DATE :

March 8, 1989

REPORTING PERIOD:

July 1, 1988 to

December 31, 1988

PERIOD OF PERFORMANCE:

September 28, 1987 to

September 28, 1988

\section{CONTRACT OBJECTIVE}

The primary objective of this Phase I MHD Seed Recovery and Regeneration Contract is to demonstrate conceptual feasibility of a potassium recovery process based on sulfate reduction and subsequent sulfur release. Bench-scale tests of the key unit operations will be conducted. These tests will provide sufficient process information to design and cost estimate a $30 \mathrm{Mw}(t)$ Proof-of-Concept demonstration facility. A cost estimate for application of the technology to a commercial scale $300 \mathrm{Mw}(\mathrm{t})$ MHD system will also be prepared.

\section{TECHNICAL APPROACH}

The project team assembled by the prime contractor, Babcock \& Wilcox, includes Westinghouse Electric Corporation, Argonne National Laboratory, and the University of Tennessee Space Institute. The technical tasks in this study are:

1.) Potassium Sulfate Reduction:

2.) Seed/Ash Separation:

3.) Potassium/Sulfur Separation:

4.) Unit Operation Evaluation and Selection

5.) Design and Cost Estimate for

a. Proof-of-Concept Plant

(W) and ANL

(W) and UTSI

$B \& W$ and $(W)$

Al1

B\&W, Hudson Engr.

\section{PROGRESS SUMMARY}

The bench-scale experimental work on the $\mathrm{K}_{2} \mathrm{SO}_{4}$ reduction process was completed. The gas/solids (kiln type) process proposed by Westinghouse was selected for this study. Bench-scale tests at B\&W and the University of Akron confirmed that design data from commercial (sodium based) paper mill recovery systems can be applied to this (potassium based) sulfur removal process. The conceptual design and cost estimate for a $300 \mathrm{Mw}(\mathrm{t})$ seed regeneration process in the original propisal was updated based on these data. A design and cost estimate for a proof-of-concept plant was prepared. The Final Report on Phase I and Proposal for Phase II (Design, Construction, and Testing of a POC Seed Regeneration Plant) were submitted to DOE/PETC in October, 1988. 
4. PLANNED ACTIVITIES

The submittal of the Final Report and Proposal for Phase II completes work on this contract until DDE completes evaluation of the Phase II proposals and announces an award for Phase II. 
CONTRACT TITLE AND NUMBER:

MHD Seed Regeneration Project

AA-70/ANL 49747

CONTRACTOR:

Argonne National Laboratory

9700 South Cass Avenue

Argonne, IL 60439

PROJECT MANAGER:

Dr. William M. Swift

(312) /972-5964
DATE:

January 20, 1989

REPORTING PERIOD:

From: June 1, 1988

To: September 30, 1988

PERIOD OF PERFORMANCE:

From: October 1, 1987

To: September 30, 1988

1. Contract Objective

The objective of this project was to obtain design information for the development of a seed regeneration process based on a molten seed reduction reactor $\left(\mathrm{K}_{2} \mathrm{SO}_{4}\right.$ to $\left.\mathrm{K}_{2} \mathrm{~S}\right)$ followed by a modifled Tampella process for the recovery of potassium as $\mathrm{K}_{2} \mathrm{CO}_{3}$. The work was in support of the B\&W Phase I Seed Regeneration Project.

\section{Technical Approach}

Bench-scale kinetic experiments were conducted to determine the rate of reduction of $\mathrm{K}_{2} \mathrm{SO}_{4}$ to $\mathrm{K}_{2} \mathrm{~S}$ in a high-temperature molten-pool reactor. Thermodynamic and phase-tquilibrium calculations were also performed to determine potential interactions between the molten seed and the ash in the coal (reductant). The data were used to develop a process flowsheet and the required heat and mass balances for the molten-salt reduction step in a proofof-concept seed regeneration plant. In addition, experiments were conducted to identify suitable refractories for the full-scale reartor.

\section{Progress Summary}

Process Thermodynamics. The thermodynamics of the reduction reaction $\left[\mathrm{K}_{2} \mathrm{SO}_{4}+2 \mathrm{C}=\mathrm{K}_{2} \mathrm{~S}+2 \mathrm{CO}_{2}\right]$ was studied using the SOLGASMIX chemica] and phase equilibrium computer program. The analysis investigated the effects of temperature $(1000$ to $1300 \mathrm{~K})$, air-to-fuel stoichiometric ratio $(0.45$ to 0.85$)$ and seed-to-coal ratio $(1.0$ to 3.5$)$ on the distribution of potassium in the reaction products. A system of 16 elements and approximately 100 relevant compounds was considered. The results of the calculations were used to estimate the potential "loss" of $\mathrm{K}$ during the reduction of $\mathrm{K}_{2} \mathrm{SO}_{4}$ to $\mathrm{K}_{2} \mathrm{~S}$ as a function of temperature, stoichiometry, and seed-to-coal ratio. The results of the thermodynamic simulations indicated that in order to minimize the potential loss of $K$, the reduction process should be operated at or below 1100 $K$, at an overall stoichiometry equal to or less than 0.65 and a seed-to-coal ratio in the range of 1.5 to 2.5 . The results of the thermodynamic analysis were also used together with the kinetic results (see below) to calculate the heat and mass balance for the flowsheet of the molten-pool reactor reduction step.

Refractory Testing. Fourteen refractories were tested for their compatibility with a $\mathrm{K}_{2} \mathrm{~S}_{2} \mathrm{~K}_{2} \mathrm{SO}_{4}$ seed mixture. The samples were machined into the shape of a cylindrical cup, filled with a mixture of $\mathrm{K}_{2} \mathrm{~S}_{2} / \mathrm{K}_{2} \mathrm{SO}_{4}$, and then 
heated to $1000^{\circ} \mathrm{C}$ in a high-temperature autoclave reactor for up to $100 \mathrm{~h}$ in a reducing atmosphere. The refractory specimens were then sectioned and examined for penetration and/or corrosion of the refractory by the seed mixture. The results indicated that several magnesia-chromia spinels and magnesia spinels (as well as a high alumina specimen) were resistant to penetration and/or reaction with the molten alkall salts. Although these refractories exhibited good corrosion resistance, additional tests would be required to determine the ability to withstand thermal cycling and the mechanical stresses of a dynamic system.

Kinetic Experiments. The kinetics of the reduction reactions were investigated in a bench-scale reactor. The reaction vessel was 15.2-cm I.D. by $40.6 \mathrm{~cm}$ deep. Initially, attempts were made to continuously feed sulfated seed and coal (reductant) to the reactor vessel to determine the conversion of the $\mathrm{K}_{2} \mathrm{SO}_{4}$ to $\mathrm{K}_{2} \mathrm{~S}$ as a function of residence time, seed-to-coal ratio, air-tocoal ratio and reactor temperature. As a result of serious problems encountered in feeding solids to the small high-temperature reactor, the majority of the tests were conducted on a batch basis using a reducing gas mixture of $30 \% \mathrm{CO} / 10 \% \mathrm{CO}_{2} / 70 \% \mathrm{~N}_{2}$. The progress of the reaction (reaction rate and conversion) was followed by measuring the change in the $\mathrm{CO}_{2}$ concentration in the reactant gas. The kinetic data was then used with the thermodynamic analysis to develop a process flow sheet and tile necessary mass and energy balance data. The selection of a separate reactor (gasifier) to generate the reducing gases from the coal was based on: 1) the difficulty in feeding a seed/coal mixture below the surface of a liquid melt; and 2) the potential formation of high amounts of $\mathrm{K}_{2} \mathrm{SiO}_{3}$, a water soluble compound that would be difficult to treat in the Tampella process.

Report. A report of the results was submitted to B\&W for inclusion in the final report of the B\&W Phase I Seed Regeneration Project

\section{Planned Activities}

In a selection process, Babcock and wilcox elected to proceed with the Westinghouse kiln reactor for the reduction step during Phase II of their seed regeneration process development program. As a result, no additional work is planned to develop the molten-pool type reduction reactor.

5. Schedule (attached) 


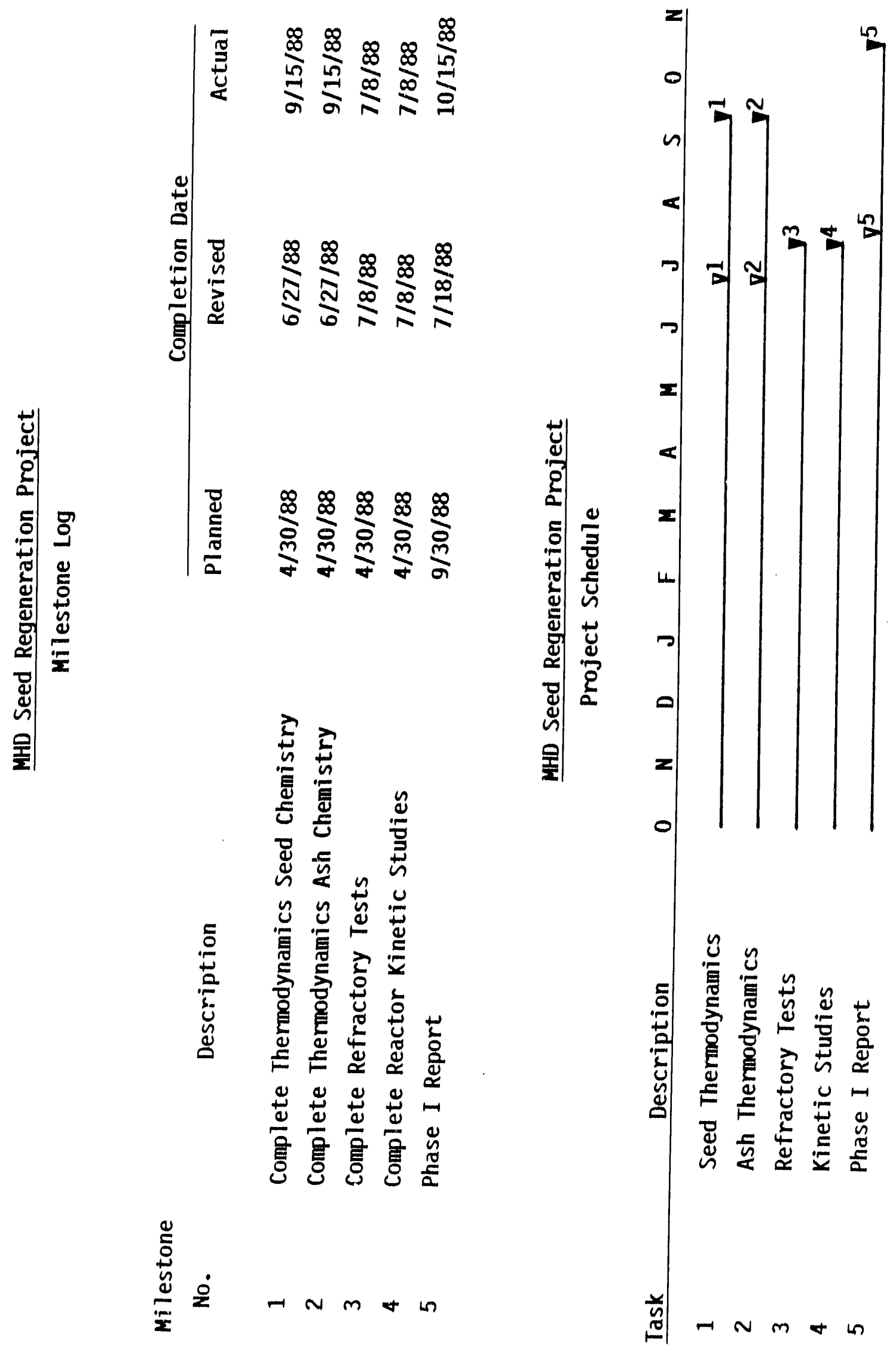


CONTRACT TITLE AND NUMBER:

MHD Heat \& Seed Recovery Technology Project

ANL-70/ANL 49745

CONTRACTOR:

Argonne National Laboratory

9700 South Cass Avenue

Argonne, IL 60439

PROJECT MANAGER:

Dr. William M. Swift

(312) /972-5964
DATE:

January 20, 1988

REPORTING PERIOD:

From: June 1, 1988

To: December 31, 1988

PERIOD OF PERFORMANCE:

From: July 1, 1976

To: September 30, 1989

\section{Contract Objective}

The objective of this project is to address technical issues related to the integration of the MHD topping and steam bottoming cycles. Through modeling and experimentation, design information will be obtained that can be used in conjunction with the proof-of-concept testing at the CFFF and CDIF to reliably integrate the MHD topping and bottoming cycles in the design of the firstgeneration MHD retrofit plant.

\section{Technical Approach}

Since 1976, Argonne National Laboratory (ANL) has been investigating problem areas related to the design of an MHD steam plant. Computer models of the important chemical and transport processes have and are continuing to be developed in support of experimental activities at ANL and other MHD test facilities to provide the necessary component and system design information for the design of the first-generation MHD plant. Work during the current reporting period focused on, (1) completing the modification of the ANL 3-D channel code to incorporate a multigrid solution algorithm for improved speed and accuracy of computation, (2) the analysis of radiation heat transfer data obtained in the FEUL facility, and (3) the testing of alloys for the steam and air-heater convective sections of the MHD steam plant.

\section{Progress Summary}

3-D Channel Code. During the reporting period, additional verification testing of the multigrid 3-D channel model was completed. The code was used to analyze experimental data reported for the Mark II MHD generator of the Institute of Electrical Engineering in Beijing, China. The code predictions of axial pressure distribution, Faraday voltage and current, and the total extracted power were in good agreement with the reported experimental data. The code and the user's manual were submitted to DOE for review. Release of the code and the user's manual to the National Energy Software Center has been delayed pending the comments of the reviewers selected by DOE to evaluate the code. Although the reviewer's comments are expected during the montin of January, 1989, final release of the code could be delayed an additional one to two months depending on the complexity of the reviewer's comments.

Materials Studies. Test data obtained on the corrosion of several ASME.coded alloys and their weldments at conditions simulating the maximum and intermediate temperature conditions of the ITAH were presented in the previous 
report and at the 1988 SEAM Conference. During the reporting period, a topical report on the result of the air heater tests was prepared and issued to the MHD community. Tests were also initiated to evaluate various alloys at the anticipated conditions of the steam superheater tubes in the MHD retrofit plant. Exposure of the selected alloys at gas and metal temperatures of 2200 and $1050^{\circ} \mathrm{F}$ will reach $2000 \mathrm{~h}$ during the month of February, 1989. A visual examination of the specimens after $500 \mathrm{~h}$ of exposure revealed no obvious signs of serious corrosion. Due to the extensive corrosion of nearly all the ITAH alloys examined during the earlier tests, a meeting has also been held with the other bottoming cycle contractors to discuss additional test work related to the issue of alloys for the intermediate temperature air heater.

A contract has also been put in place between TRW and ANL for ANL to provide support in the evaluation, testing and identification of alloys for the TRW slagging combusior. Preliminary results from this activity should be available for the next report.

Radiation Heat Transfer. As reported previously, thermal transients in the data from the latest radiation heat transfer tests conducted in the ANL FEUL facility prevented definitive determination of the $\mathrm{K}$-atom effect on total gas emissivity and comparison with model predictions. Additional effort to resolve the apparent thermal transients and/or to define additional radiation heat transfer tests has not been completed. Due to the Importance of rindiation heat transfer to the performance of such critical components as the radiant boller and slagging combustor, efforts are continuing to resolve the issues related to testing in the FEUL facility. Additional tests to assess both K-atom and slag particle contributions to radiation heat transfer are planned.

Nox Kinetics. Although some preliminary planning has been done with respect to the design of a small-scale one-dimensional flow reactir for obtaining kinetic data on $\mathrm{NO}_{\mathrm{x}}$ decomposition, progress on this task has been delayed. Efforts will be expedited during the coming months to complete the design analysis and begin fabrication and assembly of the experimental equipment.

Particle Evolution Analysis. During the current reporting period, a draft of a paper presenting the results of the analysis of particle size and number density data (obtained by Mississippi State University during tests at MSU and the ANL FEUL facility)) using the ANL particle evolution code, EVOL, was submitted to a journal for publication. The article has been accepted for publication. A topical report will also be issued on the results of this work following the final submission of the paper for publication.

Fouling. Effort during the current reporting period has also been directed toward the completion of two topical reports that will present, a) the results of the most recently completed fouling experiments in the FEUL facility, and b) a more general report summarizing the ANL fouling test program.

\section{Planned Activities}

Following the receipt and incorporation of the reviewer's comments, the 3-D channel code and associated user's manual will be made avallable to the MHD community through the National Energy Software Center. Work on the design and fabrication of a system for measuring $\mathrm{NO}_{x}$ kinetics will be expedited during the remainder of the current fiscal year. "The materials work will continue with 
the completion of the superheater materials tests and the initiation of additional air heater materials tests. The evaluation of suitable alloys for the TRW slagging combustor is a new initiative that is just getting underway. Work on radiation heat transfer and the topical reports related to fouling and the particle evolution analysis are scheduled to be completed.

5. Schedule (attached) 


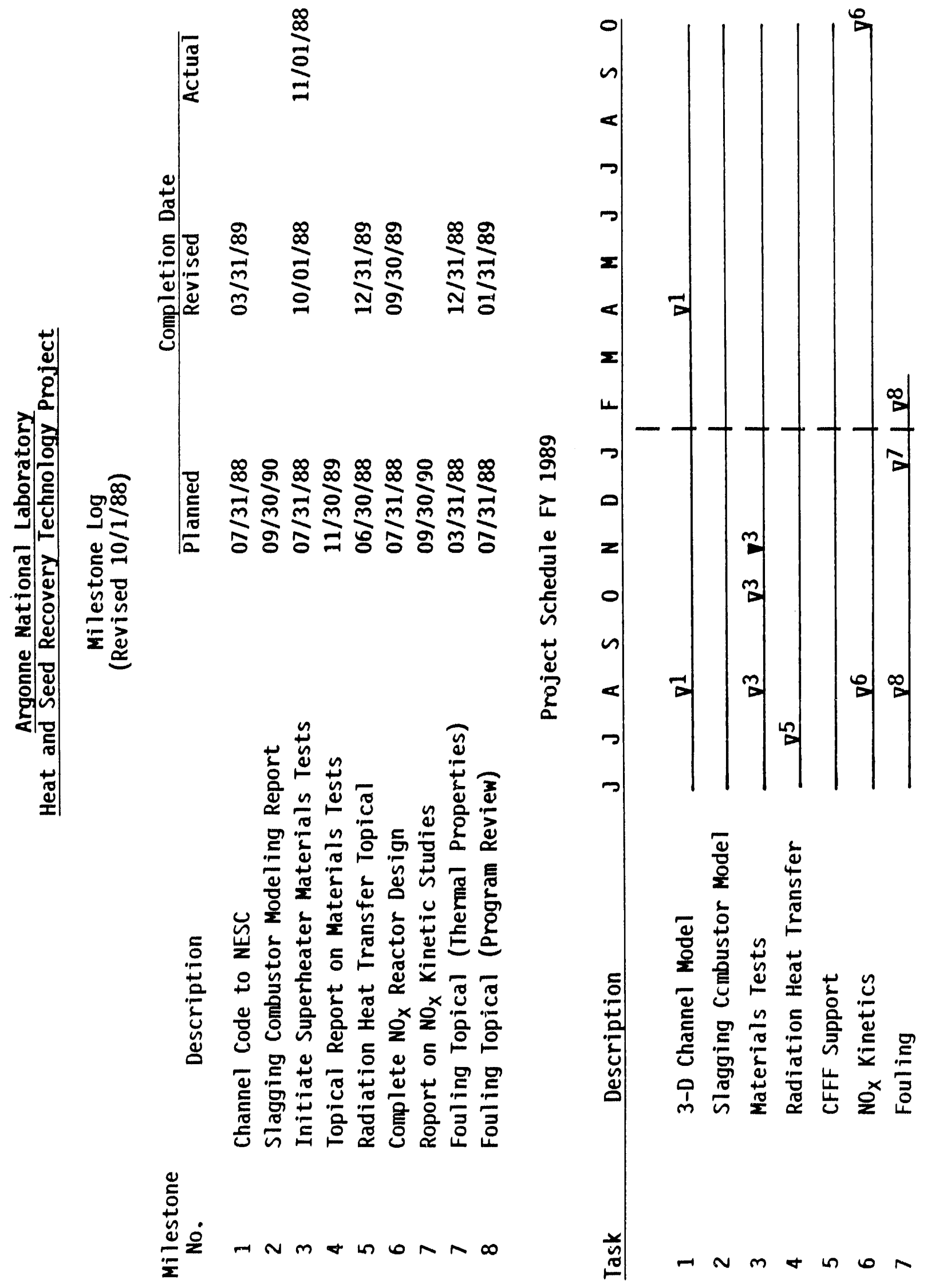


CONTRACT TITLE:

MHD Seed Recovery and Regeneration Based on the Formate Process DE-AC22-87PC79671

CONTRACTOR:

The University of Tennessee Space Institute Tullahoma, Tennessee 37388

PROJECT MANAGER:

A.C. Sheth

(615) 455-0631
DATE:

January 1989

REPORTING PERIOD:

July 1988 to

January 1989

PERIOD OF PERFORMANCE

September 1987 to

October 1988

\section{CONTRACT OBJECTIVE}

The DOE sponsored program at the University of Tennessee space Institute (UTSI) is part of the DOE's two phase program targeted at achieving the proof-of-concept ( $P O C$ ) scale testing of the most suitable seed recovery and regeneration concept. The objectives of this DOE program include:

- Generate necessary design data base for selected seed regeneration option

- Evaluate potential to recycle $>90 \%$ of potassium in sulfur-free form

- Generate reliable overall cost for a $300 \mathrm{MWt}$ plant

- Include capital, operating and maintenance cost

- Compare with flue gas scrubbing option

- Determine buildup of impurities and identify/develop methods to control the buildup of undesirables

- Determine environmental acceptabllity and identify appropriate disposal methods

Evaluate impact on MHD system economics and performance

2. TECHNICAL APPROACH:

To accomplish the above objectives in Phase I, the following approach was used:

- Refine/re-evaluate process configuration and feed stream definitions.

- Design, procure, and construct bench scale test equipment. 
- Develop a test plan for bench scale testing.

- Perform bench scale tests.

- Evaluate bench scale data.

- Upgrade POC and $300 \mathrm{MWt}$ plant designs and costs.

- Compare with FGD option.

- Report results tdentifying data needs for Phase II testing (e.g., reliability, etc.).

- Prepare and submit a Phase II proposal.

The activities described above were grouped into five major tasks for ease of monitoring the progress of the Phase I efforts.

- Task 1 - Design and set-up bench scale experimental test equipment

- Refine and re-evaluate process configuration and feed stream definitions

- Construct bench scale test equipment

- Task 2 - Bench scale testing

- Develop bench scale test plan

- Perform bench scale tests for key processing steps

- Task 3 - Evaluation of bench scale tests

- Test 4 - Upgrade $P O C$ and $300 \mathrm{MWt}$ plant designs

- Compare economics with FGD option

- Identify data needs and potential areas of improvement to be achieved in POC plant

- Test 5 - Project reporting and management

\section{PROGRESS SUMMARY}

A11 of the tasks described above were successfully completed. The Phase I final report was submitted to DOE/PETC. In the Phase I efforts, the following key steps of the formate-based seed reprocessing option were evaluated at the bench scale level:

- Dissolution of baghouse/electrostatic precipitator (BH/ESP) material

- Lime digestion of slag (i.e. potassium aluminosilicates) 
- Settling, filtration and centrifugal separation of the feed stream to the formate reactor

- Batch and continuous mode of formate reactor operations

- Flitration and cake washing of the formate reactor product and/or slag leaching product $\mathrm{mix}$

- Oxidation of formate to carbonate

- Evaporation of formate containing solution

Also, the bench scale and large scale testing to select a suitable dryer for drying the formate solution to dry powder/flakes was carried out at the sites of two prospective vendors.

Results obtatned from the bench scale tests and those carried out at the vendor sites were evaluated and utflized in developing/updating the plant design and cost estimate for a $300 \mathrm{MWt}$ plant. The Phase I results were also ut lijzed in designing each major component of the proposed proof-of-concept (POC) scale plant to develop reltable cost estimates and meaningful design data base for the subsequent large scale/commercial plants.

The following major advantages and experimental results for a formate based seed reprocessing system were confirmed and verified:

- More than $96 \%$ of the total potassium coming out from the MHD power plant as spent seed material and slag is recovered and returned to the MHD combustor in a $>97 \%$ sulfur-free form.

- Either option of recycling regenerated seed as formate or carbonate is available.

- Major chemical reaction steps (i.e. potassium extraction from insoluble aluminosilicates and formate reaction) can be carried out in one reactor $\left(235^{\circ} \mathrm{C}\right.$, CO pressure $30 \mathrm{~atm},<20$ minutes residence time) and with less processing steps than the other processes currently being evaluated.

- Flocculant reduces settler size ten fold

- Slag leaching products precoat enhance formate product filtration

- The estimated budget capital cost* of the $300 \mathrm{t}$ plant based on various optional configurations ranged from $\$ 21.7$ to $25.8 \mathrm{mi11}$ ion

* Includes escalation and al lowance for funds during construction, royalty allowance, cost of training personnel, lost incume during start-up, initial chemicals and catalyst cost, etc. as per EPRI guidelines. 
with the corresponding yearly operating expense ranging from $\$ 6.34$ to 6.85 million. In comparison, the simflar costs for the $\mathrm{SO}_{2}$-control option based on wet 1 imestone scrubbing is $\$ 50.5$ million and $\$ 7.10$ milliton respectively. The effect of impurtties and process economics for three different options (1.e. basie case, without slag leaching and without formate oxidizer) was evaluated.

Base upon this study and the process history of commerctal operations, the formate-based concept is an excellent candidate and has a high potentlal with a low risk for successful adaptation to an MHD seed reprocessing option. As such, the process requires only minimum development resulting in a savings of both time and cost.

\section{PLANNED ACTIVITIES}

The Phase I final report and Phase II revised proposal (with separate plans and cost estimate for the DOE-requested regenerated seed tests) have been submitted to DOE/PETC for review and selection. The Phase II efforts will begin as soon as DOE completes thelr selection and evaluation of the Phase II seed regeneration contractor.

\section{SCHEDULE}

Except for writing appropriate technical papers in the near future, no further activities are planned, funded or outstanding under the Phase I contract. 
CONTRACT TITLE AND NUMBER:

Conceptual Design of the Scholz MHD Retrofit Plant

Date

$D E-A C-87$ PC 79668

CONTRACTOR:

Westinghouse Electric Corporation Advanced Energy Systems Division P.O. Box 10864

Pittsburgh, PA 15236

\section{PROJECT MANAGER:}

Lawrence $E$. Van Blbber (412) 382-5158

Reporting Period

$6 / 23 / 88$

to $12 / 31 / 88$

Perlod of Performance

$9 / 87$

to $4 / 30 / 89$

1. Contract objective

The objective of this project is to develop major portions of a conceptual design of a coal-fired MHD retrofit of the SCHOLZ Generating Plant owned and operated by the Gulf Power Company, a subsidiary of Southern Company.

2. Technical Approach

The initial tasks for the conceptual design included the collection of technical data for the existing plant and preparation of the Retrofit Plant Requirements. MHD System Trade-off studies were performed to determine operating state points that minimize the plant cost of electricity. Design descriptions and sizing of the MHD systems were developed and layouts were prepared of the buildings and overall plant. Plant performance and estimates of economic value were calculated. The final tasks will include preparation of a design and construction schedule and an estimate of cost for building the retrofit systems.

3. Progress summary

During this reporting period conceptual drawings were completed for the MHD retrofit systems and interfaces with the existing facilities. Layout drawings were developed for the buildings and site. Process flow diagrams and electrical one-line diagrams were also ioveloped. 
Figures 1 and 2 are photographs of the SCHOLz Plant. Flgure 1 is a view of the rear of the plant highlighting the boller bullding and the electrostatic precipitators. Flgure 2 shows the land avallable for installing the MHD facilities. The SCHOLz plant contains two 46 MWe steam Turbine Generator Units with separate boilers and control systems. Turbine inlet conditions are 425,000 lbs/hr of steam at $900^{\circ} \mathrm{F}$ and $850 \mathrm{psia}$. The plant operates with Illinois No. 6 coal and has coal access by railroad and barge via the Apalachicola River.

During the previous reporting period MHD system trade studies and generator analyses were completed resulting in the definition of system state points and performance requirements. Key parameters are presented in Figure 3.

A conceptual design study of an integrated generator concept was developed based on the use of demonstrated AVCO electrode hardware. In developing this concept, emphasis was given to including features that would enhance fabrication, assembly and removal; increase magnet warm bore utilization; and increase reliability. A channel design concept was developed with bore dimensions of $5.5 \mathrm{~m}$ in length and a $0.4 \mathrm{~m}$ square inlet configuration. This channel contains 190 anodes and 209 cathodes.

A conceptual design of an "active" power conditioning system was developed which is based on the use of solid state current collection converters to control current at each individual electrode. Individual currents are consolidated into eight terminals that form four complete frames at relative uniform voltages and two terminals at the channel ends. Potential Defining Converters are used to control voltage of the consolidated terminals for optimizing performance. The power conditioning system design also includes transformers, filters, capacitors, a bulk inverter and protection equipment.

Design concepts were developed for the combustor, magnet and diffuser. The combustor design is based on the TRW two-stage combustor scaled to the specified operating conditions. The magnet design concept is a clrcular saddle field coil design similar to the six Tesla long Argonne National Laboratory magnet. Scaled dimensions for the retrofit application approximate those of the existing magnet. The diffuser design is based on the concept used at the UTSI facility. Design concepts have also been developed for the boller, coal handing equifment, oxidant supply and other support systems. 
Layout drawings have been developed for the bulldings housing the power train, boiler, and power conditioning and support systems. Flgure 4 is a layout of the MHD system building including the power train and the heat recovery boiler.

Plant layout drawings, process flow diagrams and electrical one-iine schematics have also been developed. Figure 5 highlights the location of the MHD systems relative to the existing facilities. Existing plant drawings have been modified to highlight the coal, steam, water, process gas and electrical interfaces.

4. Planned Activities

Near term activities include completion of Task 4 - Engineering and Construction Cost Estimate and Task 5 - Engineering and Construction Schedules. In parallel with these activities, the draft final report wili be prepared. These activities will be completed by May 1989.

5. Schedule

SCHEDULE

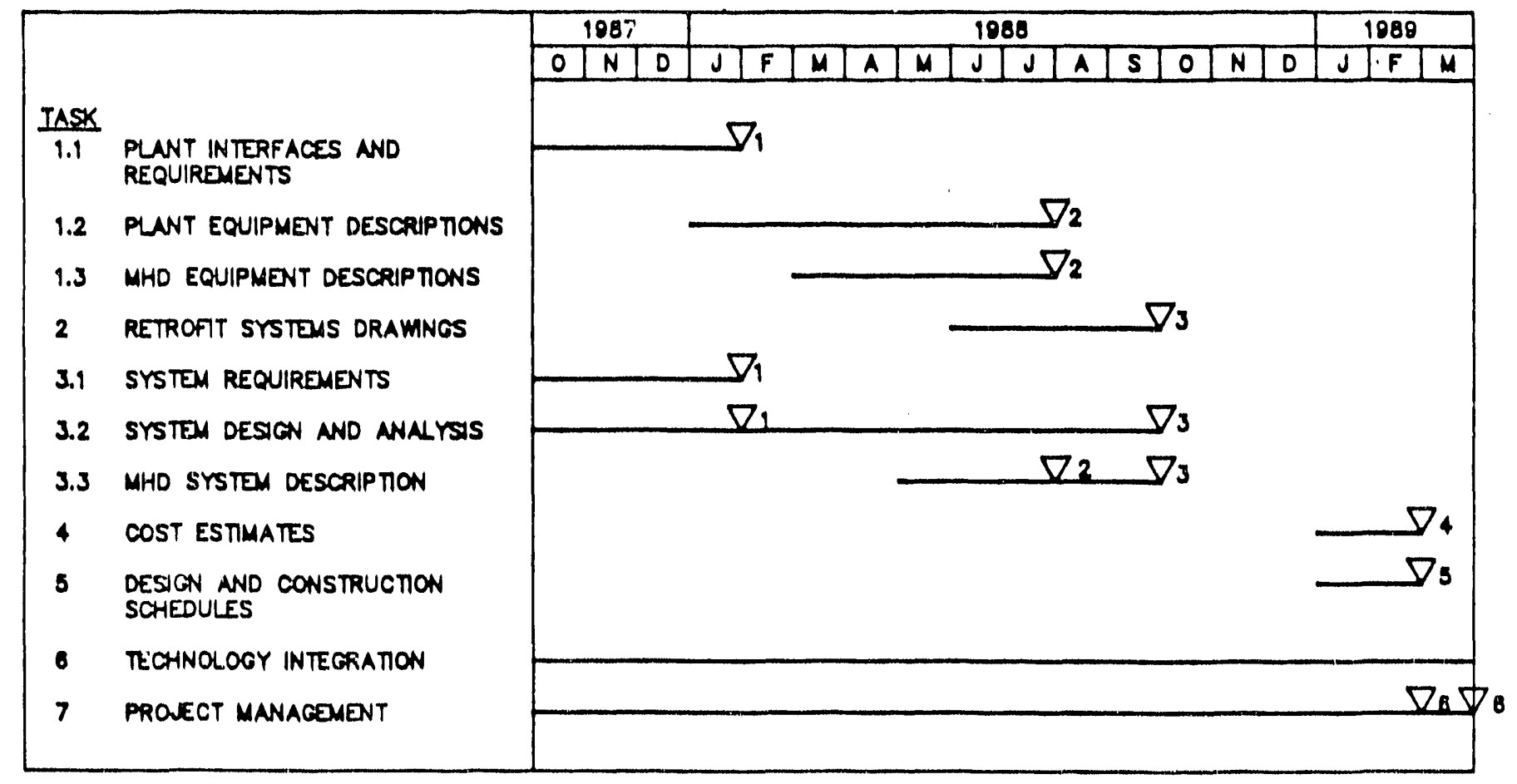

1. PLANT REQUIREMENTS AND NITIN DESICN

2. PREUMINARY SYSTEM DESCRIPTONS

7. RNATEPTIALL DESTCN
4. COST ESTMATES

b. SCHEDULES

? TINAL TEPORT 


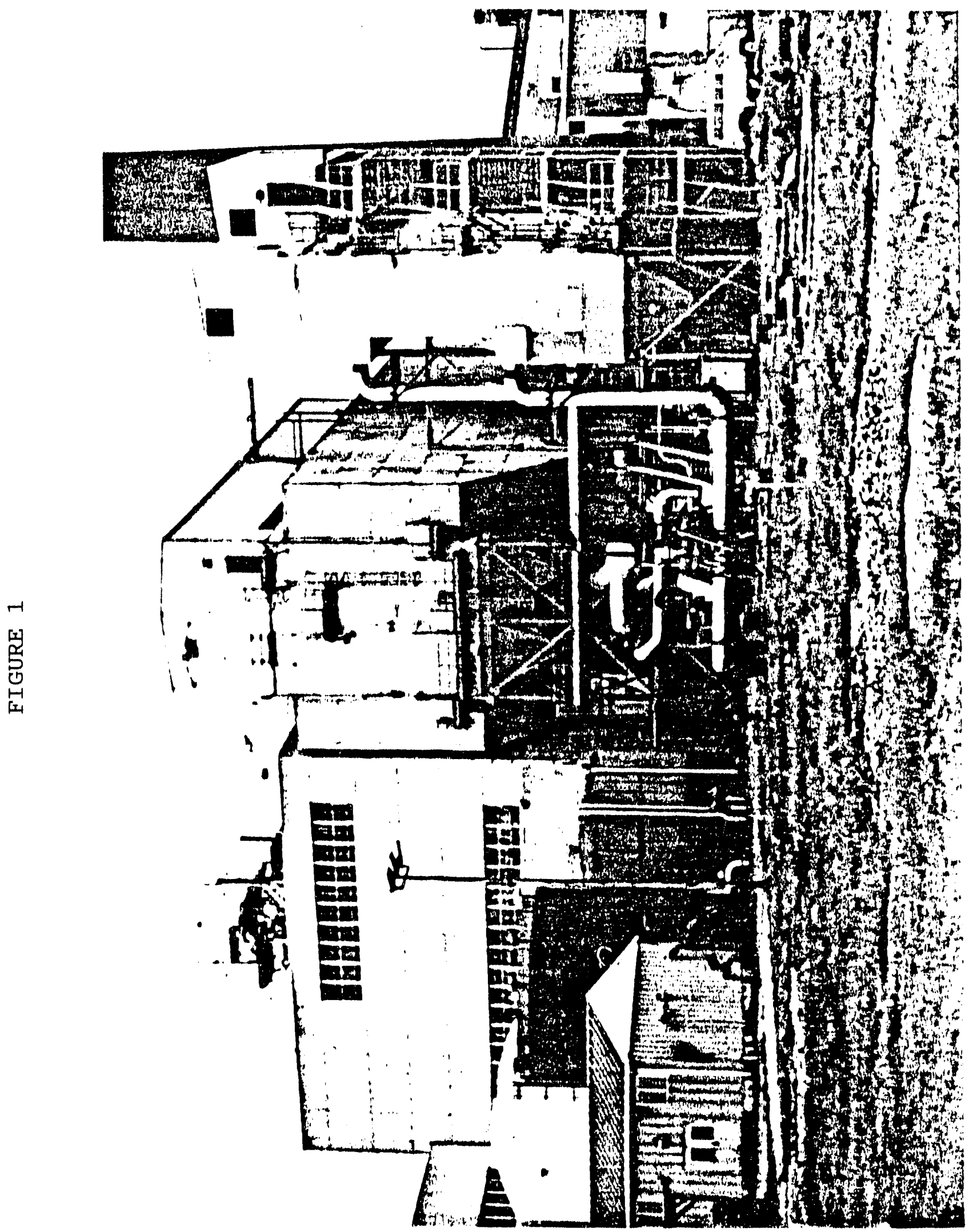




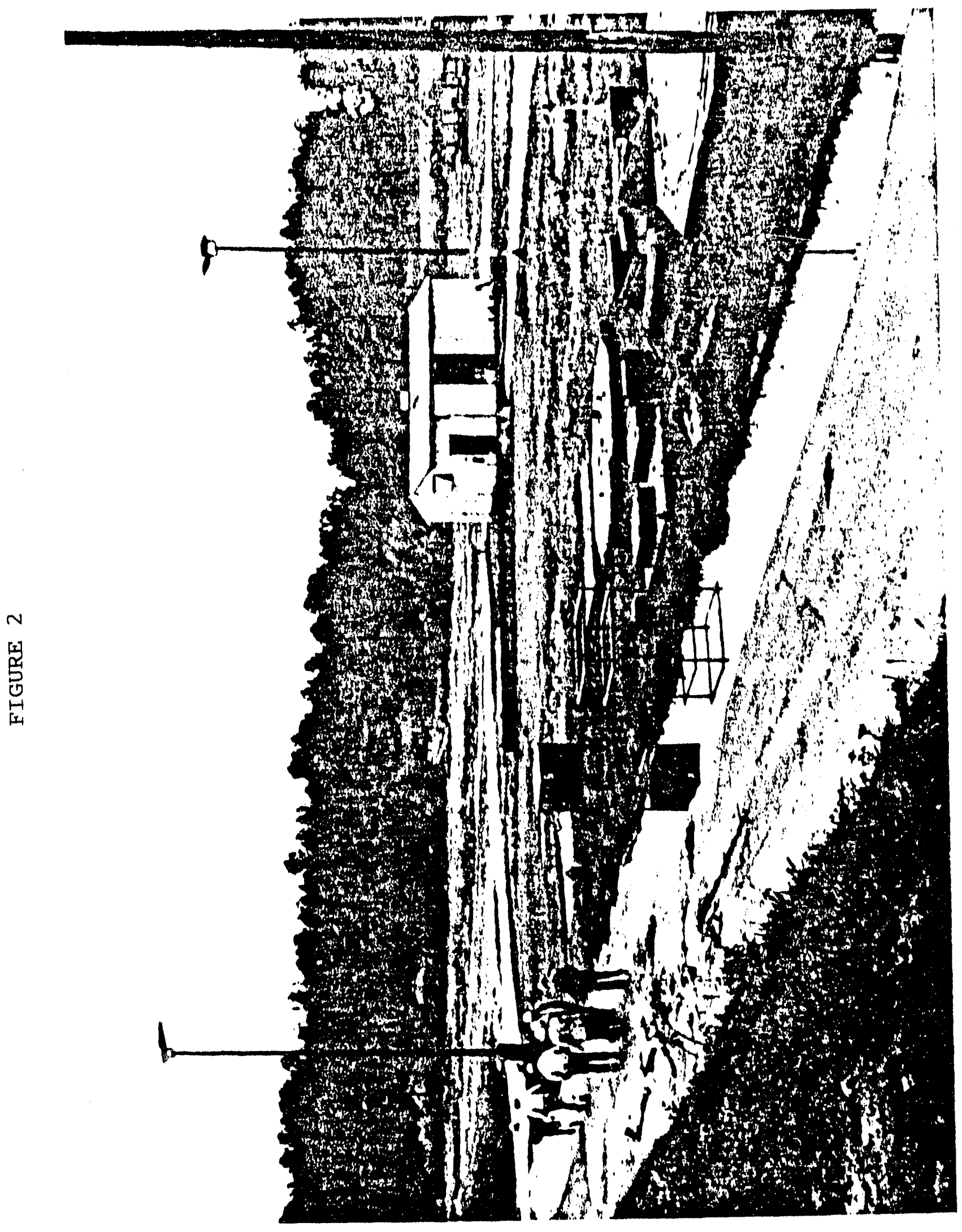




\begin{tabular}{|c|c|}
\hline Power Generated $\left(M W_{e}\right)$ & 74.4 \\
\hline MHD Generator $\left(\mathrm{MW}_{e}\right)$ & 24 \\
\hline Turbine & 50.0 \\
\hline Power Consumed ( $\left.\mathrm{MW}_{\mathrm{e}}\right)$ & \\
\hline Net system Power output $\left(\mathrm{MW}_{e}\right)$ & \\
\hline Plant Heat Rate Btu/kWh & 10 \\
\hline lant Efficiency & \\
\hline
\end{tabular}

STATEPOINTS

\begin{tabular}{|c|c|c|c|}
\hline & $\begin{array}{l}\text { Elow } \\
1 \mathrm{~b} / \mathrm{Hr}\end{array}$ & $\begin{array}{l}\text { Temp. } \\
\circ \mathrm{F} \\
\end{array}$ & $\begin{array}{l}\text { Pressure } \\
\text { PSIA }\end{array}$ \\
\hline Coal & 52,293 & 80 & 88 \\
\hline Seed & 9,364 & 80 & 88 \\
\hline oxidant & 231,438 & 1,450 & 88 \\
\hline Nozzle Inlet & 289,311 & 4,815 & 85 \\
\hline Diffuser outlet & 288,311 & 4,106 & 14.6 \\
\hline TO ESP & 373,176 & 415 & 14.3 \\
\hline
\end{tabular}


CONTRACT TITLE AND NUMBER:

Conoeptual Design of a Coal-Fired Retrofit of the J. E. Corette Plant

DE-AC22-87PC79669

CONTRACTOR:

MHD Development Corporation

P.0. Box 3809

Butte, MT 59702

PROJECT MANAGER:

Neal S. Egan

406/723-8213
DA'TE:

January 17, 1989

REPORTING PERIOD:

January 28,1988 to

January 26, 1989

PERIOD OF PERFORMANCE:

September 25, 1987 to

January 1, 1993

\section{CONTRACT OBJECTIVE}

It is the objective of this contract to perform a conceptual design of a coal-fired MHD retrofit of the J. E. Corette plant in Billings, Montana. The retroflt design project must demonstrate constructability, operabllity, rellabllity, and maintalnability, whlle providing performance and cost data for MHD systems operating within the environment of an electric utility.

\section{TECHNICAL APPROACH}

The contracting entity for this profect is the MHD Development Corporation (MDC), a consortlum of the major companies developing MHD in this country. The project team was formed by MDC and consists of AVCO Research Laboratory, Babcock and Wilcox (B\&W), Ceneral Dynamics, Montana Power Company (MPC), MSE, TRW, UTSI, and Westinghouse.

Key features of the Corette are that it is fired by subbituminous Montana Rosebud coal and that it uses a reheat cyole. The reheat cycle is typical of larger steam plants, so 1 t was a key factor in selecting the corette for a 


\begin{abstract}
meaningful demonstration design. Another kay point is that the retrofit design will utilize a steam connection between the existing plant and the Corette, 1.e., steam generated in the HRSR wlll be plped to the Corette turbine. The corette has a turbine capactty of $185.0 \mathrm{MW}_{\mathrm{e}}$ (nominal), although environmental constralnts presently restrict the output to approximately 166 $\mathrm{MW}_{\mathrm{e}}$. During MHD operation approximately $107 \mathrm{MW}_{\mathrm{e}}$ will come from the Corette boller and the remalnder (approximately $78 \mathrm{MW}_{\mathrm{e}}$ ) from the MHD steam. The MHD channel wlll produce $28 \mathrm{MW}_{\mathrm{G}}$
\end{abstract}

The overall design effort is divided into six tasks:

Task 1 - Component Identification and Description

Both existing plant and new components constituting the design are being identifled by type, size, and quantity. The following guidelines have been used during this conceptual design effort:

- 65\% plant capacity factor

- $85 \%$ plant operational availability

- Plant operational considerations in the range of $75-100 \%$ of design

- Each of the MHD components is to be designed for a continuous operation of 4000 hours

- Rosebud coal is the referenco fuel

- Dry potassium carbonate is the seed material

- Component descriptions include appropriate sections for inspection, maintonance, and operation considerations. 
Task 2 - Plant Layout and Integration

The plant layout and integration consists of the existing J. E. Corette plant layout showing the integration of the MHD system. In addition, schematic and general arrangement drawings for major components and major piping are being prepared to depict the method if integration with thoise of the existing facility. Heat and mass balance diagrams for $75 \%$ and $100 \%$ of design are being prepared.

Task 3 - Reporting and Design Review

Reporting requirements are on a monthly basis. Pormal design evaluations are accomplished by several reviews: preliminary design definition, preliminary design review meeting, design status, and two final design reviews prior to report finalization.

Task 4 -- Preparation of Cost Estimates

An estimate of the capital costs for the MHD plant in 1988 dollars is beingr accomplished and will be presented in the conceptual design report in accordance with the DOE/NASA Code of Accounts. For operational cost considerations, an estimate of consumable costs along with credit for power delivered to the grid will be furnished. In addition, costs are being estimatod for preliminary and detajled design as well as for construction. Cost sharing possibilitios for the construction of the project are being, included, identifying sources, types, and amounts. 
Task 5 - Preparation of Design and Construction Schedules

The concoptual design report will include a schedule for accomplishing the design and construction efforts required to achieve the MHD plant addition.

Task 6 - Interfacing with the National MHD Program

MDC has been and will continue to participate in the MHD Technology Transfer Integration and Review Committee as requested.

\section{PROGRESS SUMMARY}

Task 1 - Component Identification and Description

The first portion of this task has been to define MHD operating parameters, their interrelation with Corette systems (boller performance at part load, achlevable turbine capacity, feedwater availability, coal handling, switchyard capacity, etc.) and develop a plant heat and mass balance diagram. Final heat and mass balance diagrams (100\% and $75 \%$ of design) are being rovised on the basis of analytical results provided by AVCO and MSE, and component design requirements defined by the project team. Magnetic field maps have been provided by Ceneral Dynamics to assist in determining materials of construction and water purity requirements.

Efficient. interface of the corette feedwater system and the MHD cooling water loops continues to require attention as the component designs are 
finalized. Continual vigilance is necessary to maximize heat utilization from the various sources.

Besides system integration efforts, Task 1 has included the design of the individual components. Each of the team members have specific hardware design responsibilities, and furnish this design information to MSE, the technical integrator/coordinator. Component designs have been completed and additional information on various operational aspects - part load, reliability, maintainability - are nearing completion.

Task 2 - Plant Layout and Integration

Initial estimates of component size were made and several placements evaluated. The corette plant site has sufficient area to allow the MHD retrofit to be placed in close proximity to key systems and to minimize steam and feedwater line lengths; however, placcment is it challenge as the site is restricted by natural and inan-made features (river, highway, park, residences). An initial placement of the MHD system was selected on the east side of the existing Corette plant between the Yellowstone River and track for the incoming railroad. Final layout diagrams reflecting component designs are now being prepared; however, information to date confirms the initial placement. 
Integration of the two plants wlll include these systems:

Plant Services:

\author{
Building heating system \\ Flre protection \\ Communication \\ Sanitary/storm sewers \\ Service and instrument air \\ Service water \\ Potable water \\ Service electrical \\ Raw coal supply \\ Electrical \\ Control room \\ Steam \\ Feedwater
}

Task 3 - Reporting and Design Reviews

A project team kick-off meeting was held in Billings to orient the team to their project responsibilities and to tour the corette plant. A November meeting in Pittsburgh was held by DOE-PETC to insure that MDC understood the objectives of the design effort and to request formal submittal of a Design Definition Document. This document was submitted for advisory committee and DOE review in mid-December 1987, discussed at DOE In mid-January 1988, and formally issued in February 1988. Preliminary design review meetings were held with the project team on April 21, 1988 and with DOE on April 28, 1988. A 
design status meeting was held at PETC on December 15, 1988, Comments from team members and DOE were Incorporated into the designs. Initial report Inputs have been sent to team members, consultants, and advisory committees for review. Comments will be reflected in the rough draft of the final report now being prepared for issuance this month.

Task 4 - Preparation of Cost Estimates

A standard format and form was prepared for the project team to use in submitting cost estimates. The estimates required component and system definition so this offort is now underway.

Task 5 - Preparation of Deslgn and Construction Schedules

As with the costing, scheduling requires component and system definition prior to completion, so this activity is also currently being done.

Task 6 - Interfacing with the National MHD Program

This task is primarily to support MDC's participation in the TTIRC, e.g., the June 22 meeting in Nashville. Other interface opportunities have been the meeting with DOE-PETC in November 1087, the Contractor's Review Meeting, in January 1988 and the SEAM Conference in Nashvillo in June 1988.

MDC is also participating in the January $24-26,1989$ TTIRC and Contractor's Review Meeting. 
Future participation is expected to be at the next TTIRC sem-annual meeting and the Contractor's Review Meeting in June 1989.

\section{PLANNED ACTIVITIES}

A draft of the final design report will be issued in January 1989 and review meetings will be held in late February and early March. The approved report was issued tin August 1989. 


\section{TTIRC SEMI-ANNUAL REPORT \\ Prepared by G. D. Funk \\ January 10, 1989}

CONTRACT TITLE AND NUMBER:

Operation of the Department of Energy's Component Development and Integration Facility.

Contract No. DE-AC07-781D01745

\section{CONTRACTOR:}

MSE, Inc.

P.0. Box 3767

Butte, MT 59701

\section{PROJECT MANAGER:}

J. M. Sherick

(406) $494-7300$ or FTS $587-7300$
REPORTING PERIOD:

June 21, 1988

December 31, 1988

PERIOD OF PERFORMANCE:

June 21,1988 to

December 31,1988

\section{CONTRACT OBJECTIVE:}

The Component Development and Integration Facility (CDIF) is an engineering scale, development test facility for magnetohydrodynamic (MHD) topping cycle components operated for the U.S. Department of Energy by MSE, Inc. The major objective of the CDIF is to obtain MHD test results that will provide the design basis for larger scale MHD components, which is in support of DOE's commitment to MHD development and proof-of-concept program. Included is support for the National MHD Environmental Program that provides research on environmental issues specific to MHD, evaluation of environmental test data from the CDIF and the Coal-Fired Flow Facility (CFFF), support for the development of an MHD technical data base, and ambient air quality monitoring at the CDIF.

\section{TECHNICAL APPROACH:}

MSE, Inc. has been under contract to the U.S. Department of Energy since October 1, 1978 to perform MHD component testing. The first system turnover from construction was December 1979 and initial turnover of the facility by the construction contractor occurred in February 1980.

MHD component testing began in December 1980 with initial power generation being achieved in Apri1 1981. Maximum power to date, 2.3 MWe, was achieved in September 1982. In December 1983, 3.3 MWhrs of electricity were transmitted to the commercial power grid using the EPRI-supplied inverter. 
From December 1983 through July 1984 preparations for and installation of the TRW-designed coal-fired combustor (CFC) occurred. CFC first-stage

characterization testing was completed January 30, 1985. Installation of the second stage and an upgraded channel/ditfuser was completed on May 17, 1985. The first checkout firing was accomplished on July 17, 1985 and coal-fired power generation tests on the workhorse components were initiated. On October 2, 1986 an 8-hour duration test was completed. In May and July of 1988 record peak power levels (coal generated) were attained in the diagonal and Faraday modes, respectively. From October 12, 1988 through the present, instrumentation and plant systems were modified, and the TRW coal-fired precombustor (CFPC) was installed. Checkout testing of this new hardware is scheduled beginning in February 1989. Tests on this hardware will continue until delivery of the next generation (prototypic) components.

Specific tasks to support the above include:

\subsection{Test Support}

- Channel refurbishment and repair

- Design, installation and checkout of plant modifications to support the testing program

- Plant maintenance

\subsection{Major Plant Modifications}

- Design, installation, and checkout of major plant modifications required to support the Integrated Topping Cycle (ITC) and DOE Five-Year Program Plan

3.0 Upgrade Plant Systems in Support of ITC and DOF. Five-Year Plan in the Areas of:

- Reliability

- Availability

- Maintainability

- Operability

\section{PROGRESS SUMMARY:}

During the reporting period, testing at CDIF continued with checkout of modifications to second-stage oxygen injection (improved second-stage oxygen mixing and additional injection ports), Faraday steady-state operation, and diagonal $100 \%$ slag carryover testing. Testing to support calibration of the inverter and verify the new split coal feed configuration for the CFPC was accomplished. Successful preliminary diagnostic measurements were performed by Mississippi State University. Test time for the past twelve months includes a total of 66:29 hours on coal and 36:18 hours of power generation. Testing at CDIF was shutdown during this reporting period to initiate installation of the new oil-fired vitiator (OFV) and CFPC. During the shutdown the coal-fired combustor was disassembled and inspected for wear and damage. Reassembly of the CFC incorporated several new components and extensive refurbishment to the second-stage. Considerable progress was made on channel refurbishment including 
fabrication and assembly of several new wall sections. Work in progress includes procurement of newly designed cathode end blocks for the forward peg sidewalls and newly designed cathode sidebars. A comprehensive revtew of the CDIF channel design, fabrication, assembly, installation, and operation was conducted by the ITC Team and MSE.

\section{PLANNED ACTIVITIES:}

Test plans for the next reporting perfod include checkout of the newly installed OFV and CFPC. A new post-nozzle test section for optical measurements will be fabricated, installed and tested during CFPC checkout. Installation and checkout of on-line coal flow rate and molsture measurement devices are scheduled. Hardware activities for the period include fabrication of new supersonic diffuser sections, complete assembly of new aft diagonal sidewalls, and assembly of new aft peg sidewalls.

Late CY89 activities include completion of pegwall refurbishment, checkout of the improved iron oxide/slurry injection system, and power testing using the CFPC. An all new "confirmation" channel and a full compliment of prototypic current controls will be installed and the Confirmation Test Sertes initiated. 


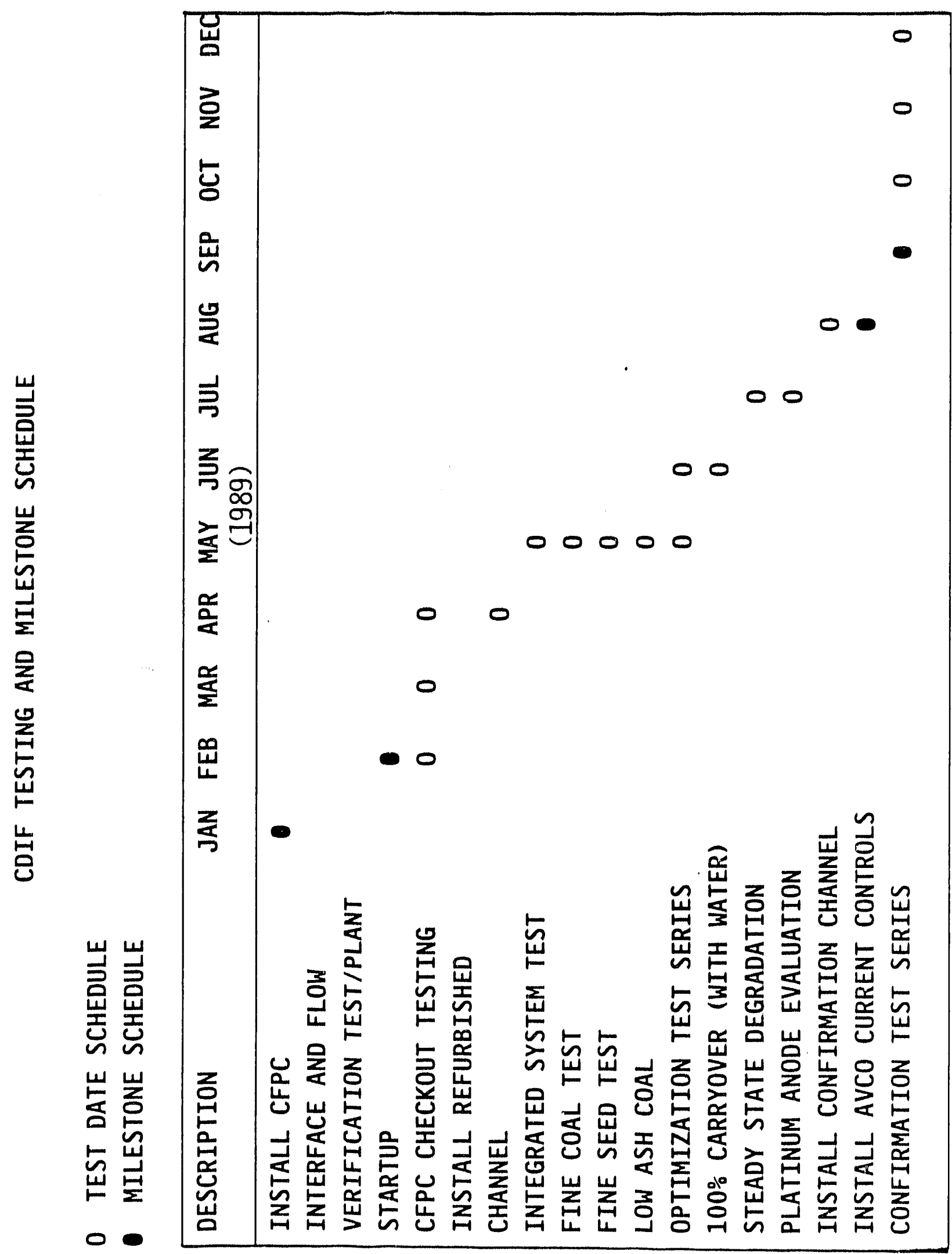


SUMMARY OF THE TECHNOLOGY TRANSFER。 INTEGRATION AND REVIEW

EXECUTIVE COMMITTEE MEETING

(October 26. 1988)

Boston. MA

The format inputs to the semi-annual reports were discussed along with the total report format and distribution. In addition to the TTIRC Charter members, the National Technical Information Center (NTIC) wlll recefve copies such that abstracts would be avallable to a wide distribution.

The MHD Power newsletter, publ ished by the MHD Industrial Forum. was handed out to about 200 representatives of the Joint Power Conference by B 111 Irving along with coples of his presented paper on MHD. The Forum said that another 200 copies were malled to the CEO's of utilities ranging in size from $500 \mathrm{MW}_{\mathrm{e}}$ to $1000 \mathrm{MW}_{\mathrm{e}}$.

B 111 Owens presented a Clean Coal Technology II schedule overlatd on the current FY'89 MHD schedule as it might apply to the MHD Retrofit of the Scholz Generating Plant or the Corette Plant. You will hear more about that in the Pittsburgh Committee meeting in January because it closely relates to Article 5 of the Committee's Charter.

A motion was passed to add to the Missing Link Subcommittee a task to "provide the TTIRC with a listing of corporations or consortiums that are engaged in bullding power generation plants and selling power to utilities. Where are they and how does one approach them."

Additional discussions were held concerning the schedule of the January TTIRC meeting and the one following the SEAM in June.

The balance of the Executive Committee meeting was spent in defining the technical interface issues that the POC program may face. Not solving the issues: Just defining them. was the aim, of the Committee.

For instance:

1. Sulfur/sulfate addition to the topping cycle:

2. Acceptablltty of alternate seeding material i.e.. potassium formate;

3. How compatible are topping/bottoming cycle and seed regeneration design conditions with the requirements of the two retrofit conceptual design studies with respect to:

a) oxidant make-up, preheat temperature and pressure

b) water coolant temperature, pressure and integration with steam cycle

c) coal specs

d) diffuser/radiant boiler interface

e) $\mathrm{NO}_{x} \cdot \varnothing_{2}$ and ASP 1 imitations

f) start-ap. part load and shutdowns

g) handling electrical faults

Finn Hals has been retained as a consultant, to Marty Bauer on the TRW Integrated Topping Cycle TTIRC. to put his arms around these issues. You will all be hearing from him in Session - 2 of this Committees meeting on Thursday. 26 January, 1989 in Plttsburgh. PA. 


\section{TECHNOLOGY TRANSFER, INTEGRATION \& REVIEW COMMITTEE (TTIRC)}

\section{Second Semi-Annual Meeting Session 1 \\ 24 January 1989}

Allegheny Room. Will lam Penn Hotel. Pittsburgh. PA

\begin{tabular}{|c|c|c|}
\hline $1: 00 \mathrm{pm}$ & Wel come and Introduction & R. Cunningham - TRW \\
\hline $1: 05$ & $\begin{array}{l}\text { Cal1 Meeting to Order and Acceptance } \\
\text { of Last Semi-Annual Meeting Minutes }\end{array}$ & $\begin{array}{l}\text { W. Irving - WMI } \\
\text { G. Staats - DOE }\end{array}$ \\
\hline $1: 10$ & $\begin{array}{l}\text { Brtef discussion of the October } 1988 \\
\text { Executive Commlttee Meeting in Boston } \\
\text { \& Agenda for Session } 2 \text { (Technical) } \\
\text { on Thursday }\end{array}$ & $\begin{array}{l}\text { G. Staats } \\
\text { R. Cunningham } \\
\text { M. Bauer - TRW }\end{array}$ \\
\hline $2: 00$ & Break & \\
\hline $2: 15$ & $\begin{array}{l}\text { Clean Coal Technology III \& IV vs. MHD } \\
\text { Activities Related to Charter } \\
\text { Article - } 5\end{array}$ & J. Shertck - MijE \\
\hline $3: 00$ & $\begin{array}{l}\text { Clean Coal Technology III \& IV vs. MHD } \\
\text { Activities Related to Charter } \\
\text { Article - } 5\end{array}$ & $\begin{array}{c}\text { J. Cuchins - So. Services } \\
\text { Company }\end{array}$ \\
\hline $3: 30$ & $\begin{array}{l}\text { DOE Requirements to Respond to any } \\
\text { Clean Coal Technology }\end{array}$ & R. Cunningham \\
\hline $3: 45$ & $\begin{array}{l}\text { Open discussion } \\
\text { A71 TTIR Committee Members }\end{array}$ & $\begin{array}{c}\text { Leaders W. Irving, } \\
\text { G. Staats }\end{array}$ \\
\hline$: 30$ & Adjournment & \\
\hline
\end{tabular}


TECHNOLOGY TRANSFER, INTEGRATION AND REVIEW

COMMITTEE (TTIRC)

\author{
Second Semi-Annual Meeting \\ Session 1 \\ 24 January 1989
}

Allegheny Room, William Penn Hotel, Pittsburgh, PA

The minutes for this meeting have not yet been approved by the general committee for distribution and are being revised. 
TECHNOLOGY TRANSFER, INTEGRATION \& REVIEW COMMITTEE (TTIRC)

Second Semi-Annual Meeting

Sesston - 2

26 January 1989

Allegheny Room. Will1am Penn Hotel, Plttsburgh. PA

$1: 00 \mathrm{pm}$

Wel come and Introduction

W. Irving - WMI

$1: 15$

Technical Issues - Objectives

M. Bauer - TRW

$1: 30$

Definition of Technical Issues:

"How compatible are Topping/Bottoming

M. Bauer

cycle and seed regeneration design

conditions for the POC Program with

the requirements \& assumptions used

for the two retrofit conceptual studies."

1. Carbonate/Sulfate addition to the topping

P. Probert - B\&W

cycle because of bottoming cycle needs

2. Acceptability of al ternate seeding material G. Ogle - TRW (i.e. potassium formate)

3. Magnetic Field strength/channel Mach no.

4. Oxidant composition \& preheat temperature

R. Kessler - AVCO for the topping cycle.

5. Topping cycle water coolant temperature/ pressure.

6. Coal Specifications

7. Diffuser/Radiant boiler interface

8. Use of additives in the topping cycle

F. Hals - Consultant

9. $\mathrm{NOx}$ and 02 differences between topping \& bottoming cycle (POC)

10. Start-up, shutdown. part load \& their effects on downstream

11. Channel loading

F. Hals

G. Ogle

P. Probert

R. Kessler

W. Owens - $G / C$

P. Probert

R. Kessler

4:00 Open Discussion - Identify other technical issues that may need investigation - al1 TTIR Committee Members

Leaders: W. Irving

G. Staats

Adjournment 
TECHNOLOGY TRANSFER, INTEGRATION AND REVIEW COMMITTEE (TTIRC)

\author{
Second Semi-Annual Meeting \\ Session 2 \\ 26 January 1989 \\ Allegheny Room, William Penn Hotel, Pittsburgh, PA
}

The minutes for this meeting have not yet been approved by the general committee for distribution and are being revised. 
15. MHD TTIRC DISTRIBUTION LIST

\author{
U.S. Department of Energy Distribution \\ Dr. Harold Chambers \\ Technical Project Officer \\ PM-20, MS 922-208 \\ U.S. Department of Energy \\ Pittsburgh Energy Technology Center \\ P. 0. Box 10940 \\ Pittsburgh, PA 15236 \\ Mr. David L. Hunter \\ Contracting officer \\ AD-22, MS 921-165 \\ U.S. Department of Energy \\ Pittsburgh Energy Technology Center \\ P. 0. Box 10940 \\ Pittsburgh, PA 15236 \\ Dr. Victor Der \\ $U$. S. Department of Energy \\ Office of Fossil Energy \\ $\mathrm{FE}-32$ \\ Washington, DC 20545 \\ General Counsel for Patents \\ U.S. Department of Energy \\ Chicago Operations Office \\ 9800 South Cass Avenue \\ Argonne, IL 60439 \\ U.S. Department of Energy * \\ Office of Technology Transfer \\ P. 0. Box 10940, MS 922 \\ Pittsburgh, PA 15236
}

*First obtain clearance from office of Patent Counsel, Chicago, then mail copies to OTT with statement, "Patents Cleared by Chicago office of Patent Counsel on (Insert Date) ". 


\section{Additional Distribution}

Dr. William Swift

Argonne National Laboratory

9700 South Cass Avenue

Argonne, IL 60439

Dr. R. Kessler

Avco Research Laboratory, Inc.

2385 Revere Beach Parkway

Everett, MA 02149

Mr. S. Petty

Avco Research Laboratory, Inc. 2385 Revere Beach Parkway

Everett, MA 02149

Dr. Steve Datsko

Babcock \& Wilcox

1562 Beeson Street

Alliance, $\mathrm{OH} 44601$

Dr. J. L. Bates

Battelle Pacific Northwest Labs

PSL Building 3000 Area

Box 999

Richland, WA 99352

Dr. Bert Zauderer

Coal Tech Corporation

P. 0. Box 154

Merion Station, PA 19066-0154

Mr. R. King

U.S. Department of Energy

Butte Project office

P.0. Box 3462

Butte, MT 59702

Mr. G. Staats

U.S. Department of Energy

Pittsburgh Energy Technology Center

P.0. Box 10940, PM-20/MS 922-208

Pittsburgh, PA 15236

Dr. R. Rosa

Montana State University

Department of Mechanical Engineering Bozeman, MT 59715
Mr. Norm Swift

U.S. Department of Energy

Chicago Operations office

9800 South Cass Avenue

Argonne, IL 60439

Dr. R. A. Carabetta

U.S. Department of Energy

Pittsburgh Energy Technology Center

P.0. Box 10940

Pittsburgh, PA 15236-0940

Mr. Leo Makovsky

U.S. Department of Energy

Pittsburgh Energy Technology Center

P.0. Box 10940, MS 922-206

Pittsburgh. PA 15236-0940

Dr. A. Cohn

Electric Power Research Institute

P.0. Box 10412

3412 Hillview Avenue

Palo Alto, CA 94303

Mr. A. C. Dolbec

Electric Power Research Institute

P. 0. Box 10412

3412 Hillview Avenue

Palo Alto, CA 94303

Dr. William Owens

Gilbert/Commonwealth, Inc.

19644 Club House Road, Suite 820

Gaithersburgh, MD 20879

Dr. Peter Marston

MIT/Plasma Fusion Center

175 Albany Street NW17-207

Cambridge, MA 02139

Dr. W. S. Shepard

Mississippi State University

D.I.A.L.

P.0. Drawer MM

Mississippi Stäte, MS 39762

Dr. C. H. Kruger

Stanford University

ïerman Mech. Eng., Room 214

Stanford, CA 94305 
Mr. L. Farrar

Montec Associates

P.0. Box 4182

Butte, MT 59702

Mr. Jack Baughman

TRW

P.0. Box 3767

Butte, MT 59702

Mr. G. Funk

MSE, Inc.

P.0. Box 3767

Butte, MT 59702

Mr. J. Sherick

MSE, Inc.

P.0. Box 3767

Butte, MT 59702

MSE, Inc.

P.0. Box 3767

Butte, MT 59702

Attn: Librarian.

Dr. W. Thielbahr

U.S. Department of Energy

Idaho Operations office

785 Doe Place

Idaho Falls, ID 83402

Mr. L. Kovalsky

Westinghouse Electric Corp.

Research and Development Center

1310 Beulah Road

Pittsburgh, PA 15235

Mr. M. Tuck

MSE, Inc.

P.0. Box 3767

Butte, MT 59702

Mr. Bob Wright

U. S. Department of Energy

Office of Fossil Energy

FE-32

Washington, DC 20545
$\mathrm{Mr}$. S. Demetriades

STD Corporation

P.0. Box "C"

Arcadia, CA 91006

Mr. C. Maxwell

STD Corporation

P.0. Box "C"

Arcadia, CA 91006

Mr. N. Johanson

University of Tennessee Space Institute

Tullahoma, TN 37388

Dr. Susan Wu

Engineering Research and Consulting, Inc.

P. 0 . Box 417

Tullahoma, TN 37388

Mr. L. Van Bibber

Westinghouse Electric Corporation

Advanced Energy Systems Division

P.0. Box 10864

Pittsburgh, PA 15236

W. Irving

WMI, Inc.

236 N. Falmouth Highway

North Falmouth, MA 02556

Dr. Carl C. P. Pian

Avco Research Laboratory, Inc.

2385 Revere Beach Parkway

Everett, MA 02149

Mr. J. M. Bauer

TRW Space and Technology Group

One Space Park, 01/1160

Redondo Beach, CA 90278

Dr. Joel Muehlhauser

Univ. of Tennessee Space Inst.

Tullahomã, TN 37388 
Dr. A. Solbes

TRW Space and Technology Group

One Space Park, 01/1181

Redondo Beach, CA 90278

Dr. R. A. Meyers

TRW Space and Technology Group

One Space Park, 01/2270

Redondo Beach, CA 90278

$\mathrm{Mr}$. Robert Arora

Houston Lighting and Power

12301 Kurland Drive

Houston, TX 77034

Mr. Robert $P$. Johnson

Pennsylvania Power and Light Co.

Two North Ninth Street

Allentown, PA 18101

Mr. Harold Bell, MS 38-75

Arizona Public Service Co.

P.0. Box 53999

Phoenix, AZ 85072

Mr. Charles Linderman

Edison Electric Institute

1111 19th Street NW

Washington, DC 20036
Mr. N. S. Egan

MHD Development Corporation

P.0. Box 4078

Butte, MT 59702

Dr. M. Petrick

Argonne National Laboratory

9700 South Cass Avenue

Argonne, IL 60439

Mr. Sam Gurol

General Dynamics Space Systems

Mail Zone 92-82.60

P.0. Box 85990

San Diego, CA 92138

Dr. Fred Walter

Montana Power Co.

40 East Broadway

Butte, MT 59701

$\mathrm{Mr}$. Finn Hals

Avco Research Laboratory

2385 Revere Beach Parkway

Everett, MA 02149 

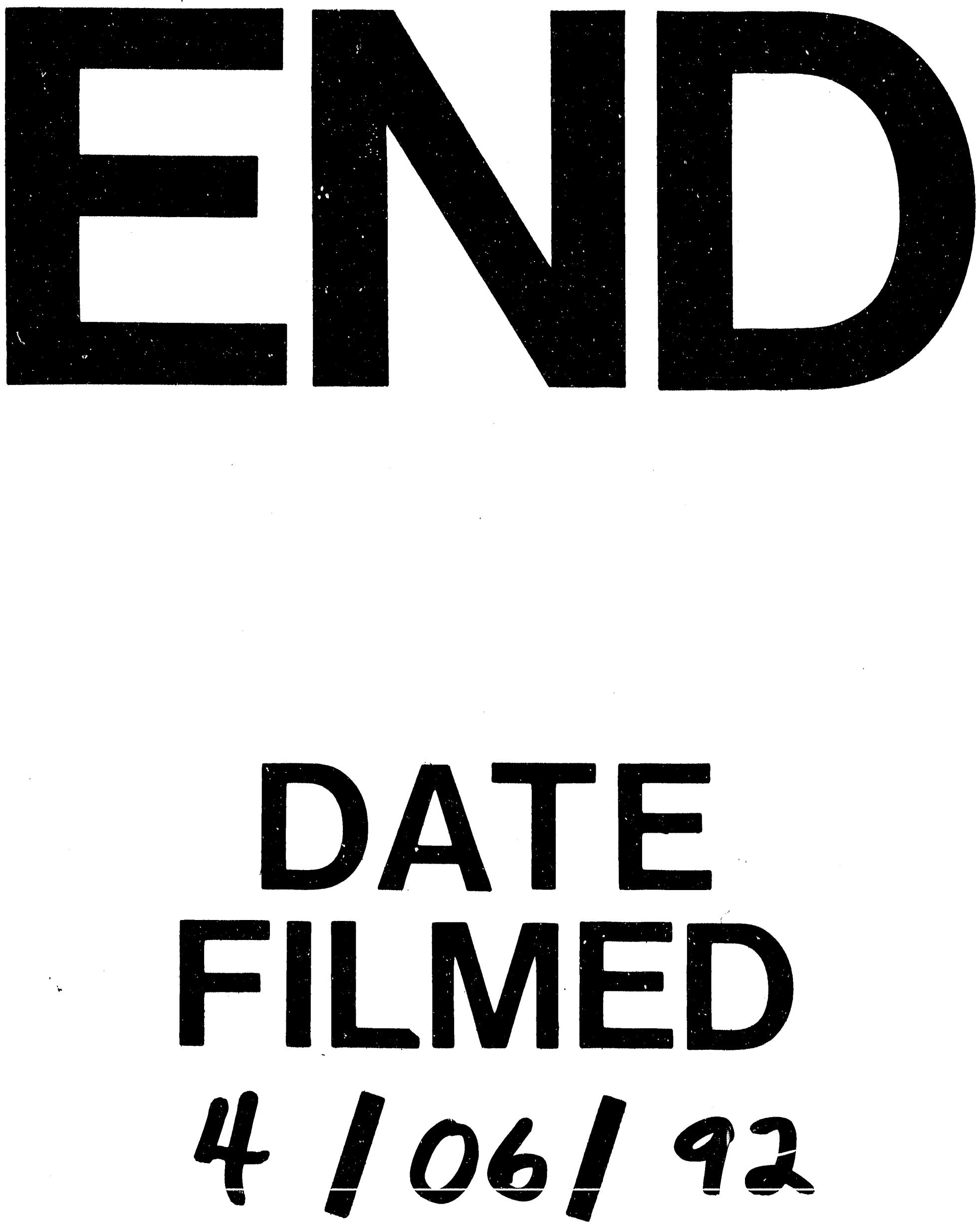
